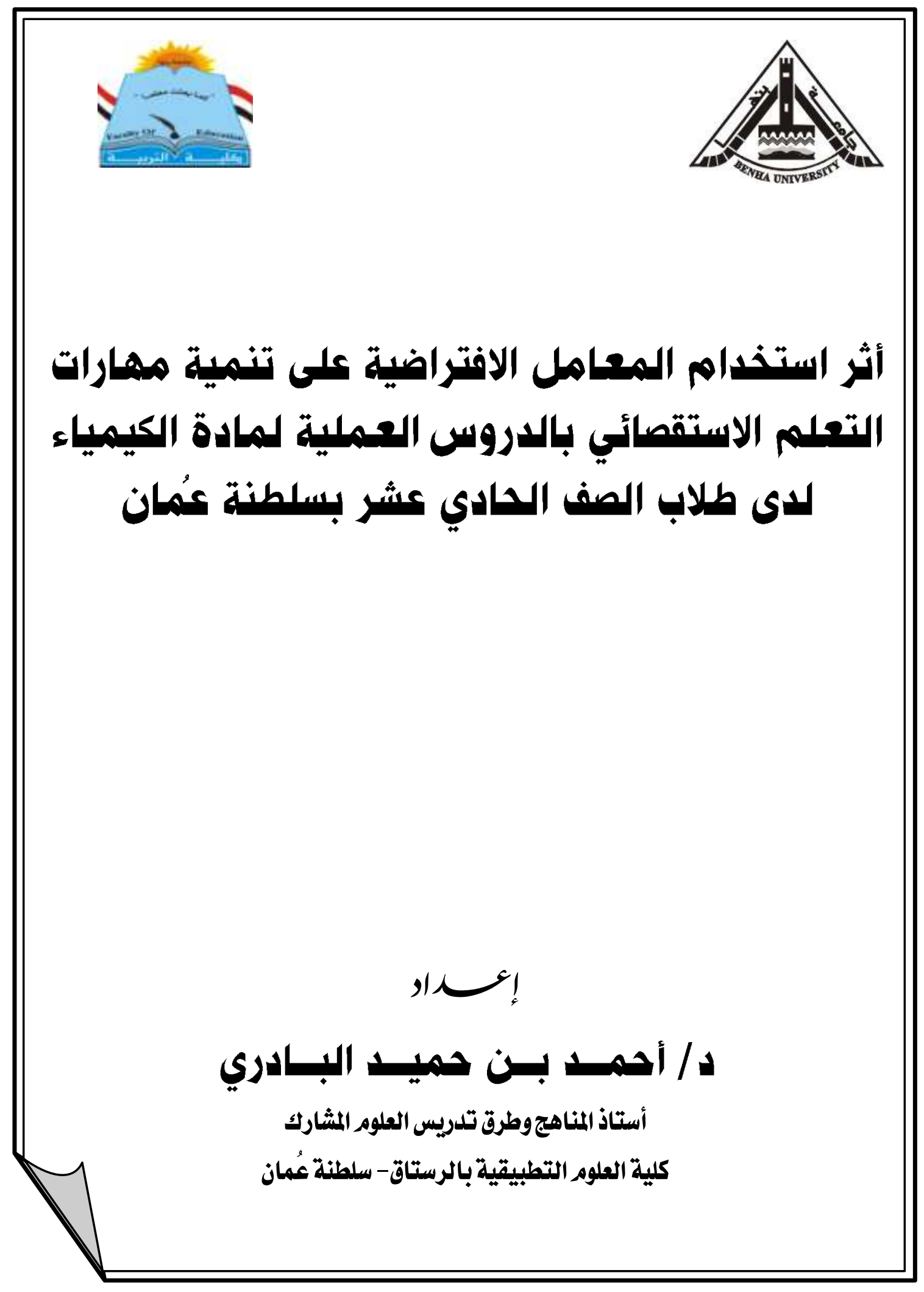




\section{أثر استخدام المعامل الافتراضية على تنمية مهارات التعلم \\ الاستقصائي بالدروس العملية لمادة الكيمياء لدى طلاب الصف الحادي عشر بسلطنة عُمان}

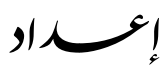

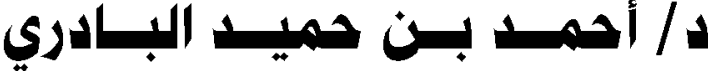

أستاذ المناهج وطرق تدريس العلوم الشارك

كلية العلوم التطبيقية بالرستاق- سلطنة عُمان

\section{الملذخ}

هدفت الدراسة إلى التعرث على أثر استخدام المعامل الافتر اضبية على تتمية مهارات

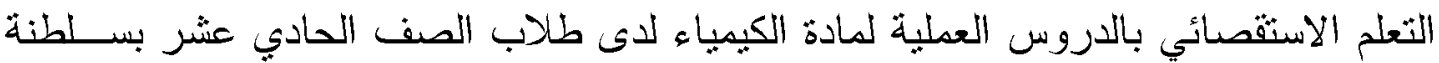

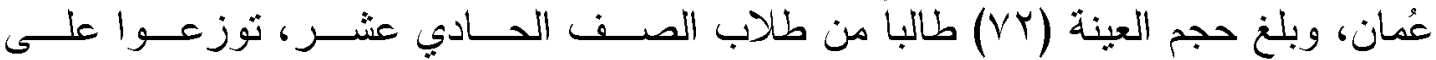

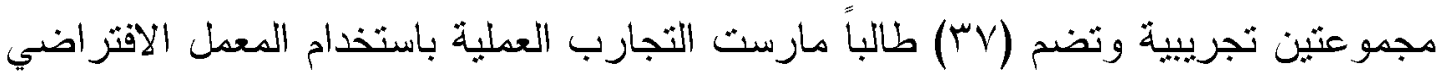
المعروف باسم (Crocodile Chemistry) ثم المعمل التقلبدي، ومجموعة ضـابطة نضـــ (ro) طالباً مارست التجارب باستخدام المعمل التقليدي فقط. لتحقيق أهداف الدراسة نم إعداد بطاقة لملاحظة وتقييم مستوى ممارســة الطــلاب

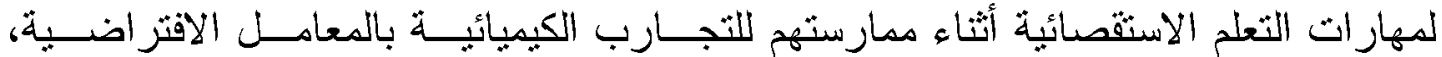
وتكونت البطاقة من (• () مهار ات رئيسية في التعلم الاستقصائي وتضم (·r) مهارة فرعية. وتم التحقق من صدقها بعرضها على المحكمين، وكما نم التحقق من ثباتها عن طريق معادلة

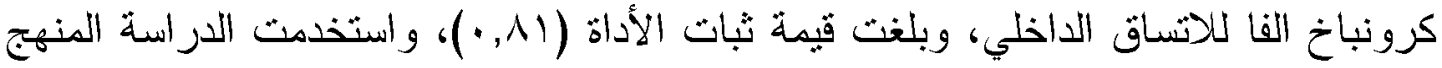

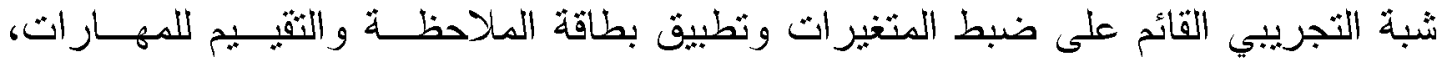

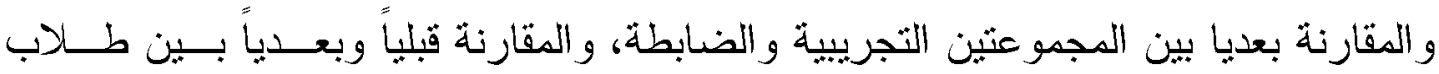
المجموعة التجريبية فقط.

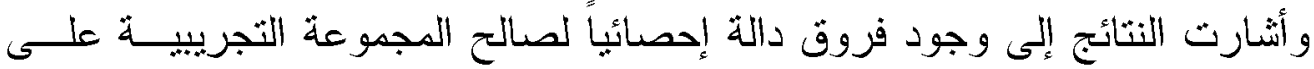

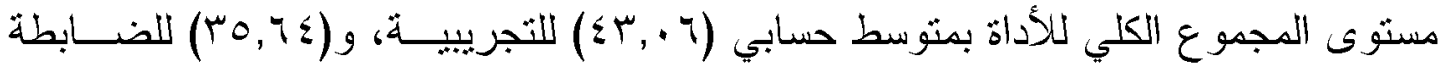

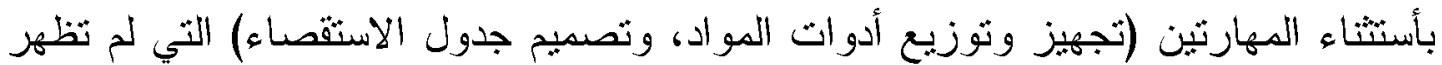


عليهن فروق دالة إحصائياً. وكان حجم الأثر لتأثير المعامل الافتراضبية على المنغير التـابع

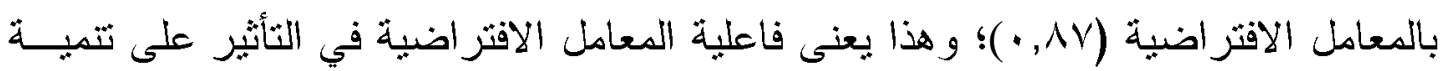

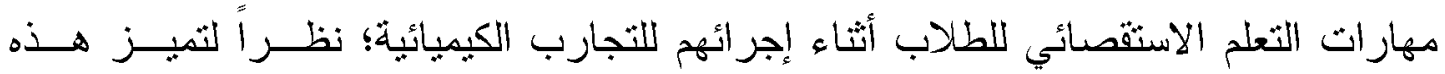
المعامل بالوضوح و التسلسل والاقة وأنها تعطي الطلاب أكثر من فرصة لممارسة التجربة.

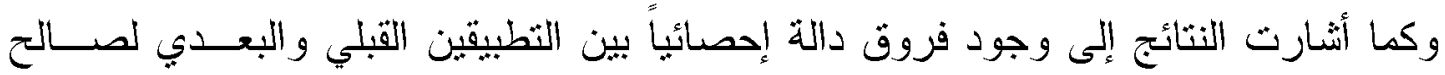

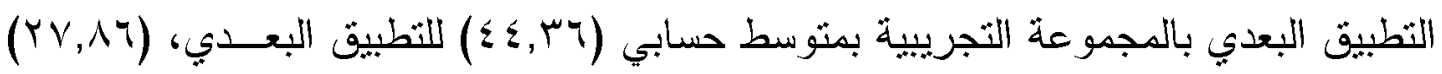

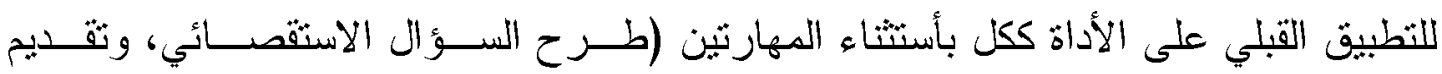
التفسير ات) و الني لم ثظهر عليهن فروف دالة إحصائياً.

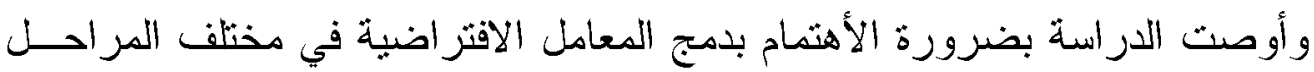

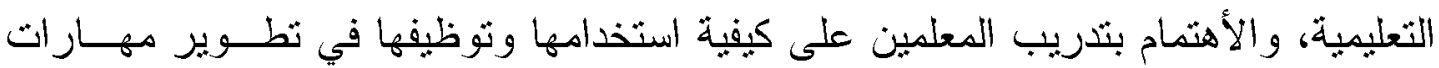
الطلاب الاستقصائية. 


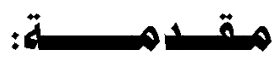

يتسم العصر الحالي بالثورة النكلنولوجية والنطورات الثنتية الهائلة الني إنعكست علـى تثافة المجتمعات، بما قدم لها من تطييقات تثنبة بسرت عمليات الإتصال و التعلم دون التقيبــد

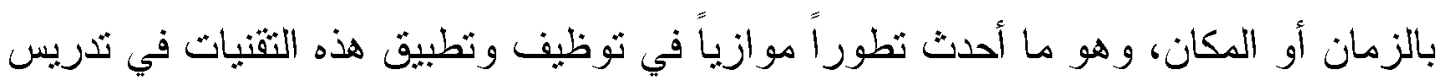

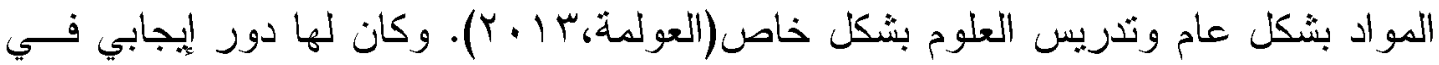
تطوير التدريس والأرثقاء بأدوار المعلم الحديثة التي تعتمد على نوظيفة للتثنيات و المعامـلـل

$$
\text { الالفتراضية في تدريس العلوم. }
$$

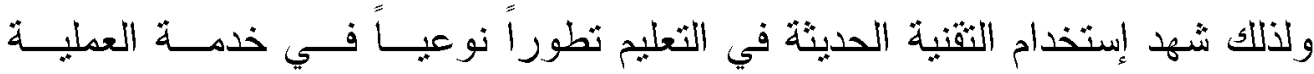

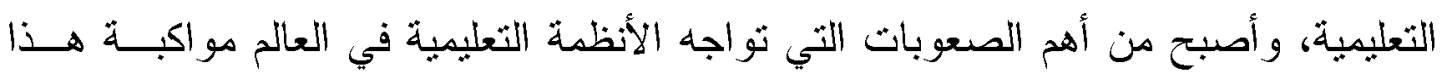

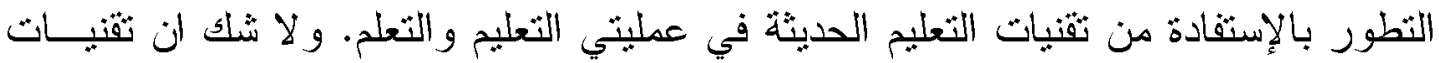

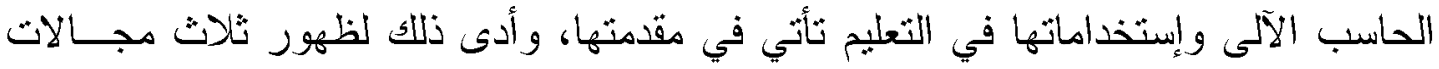

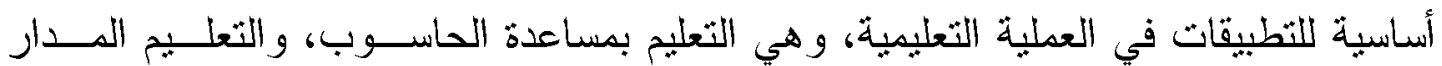

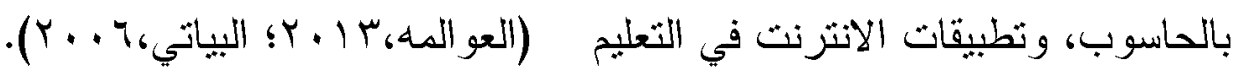

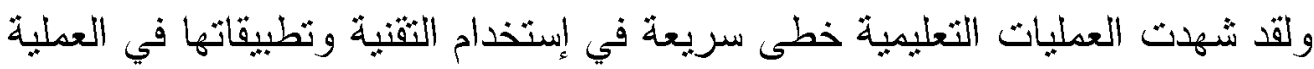

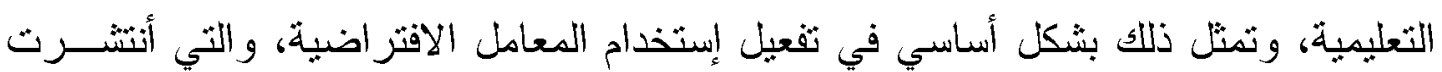

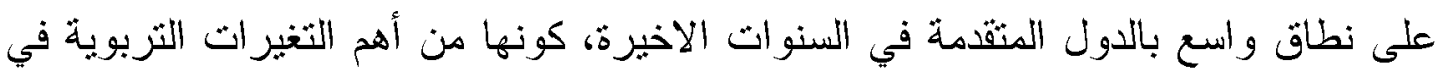

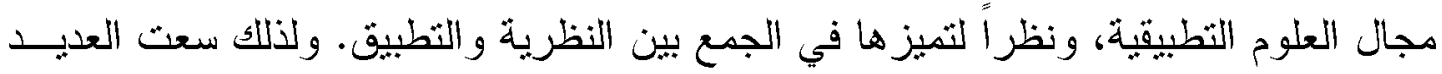

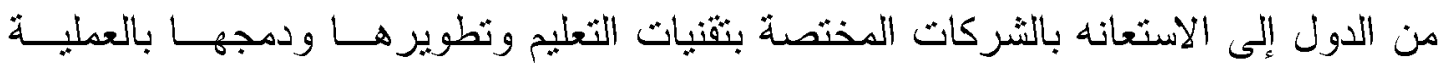
التعليمية من خلال تفعيل نقتبة المعامل الافتر اضبة كونها برامج نعليمبة قد نساعد المعلم على بلى

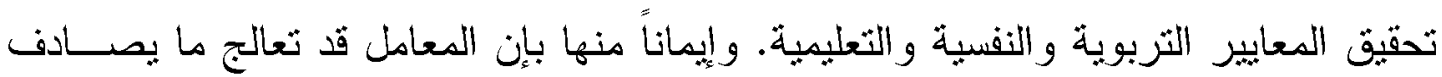

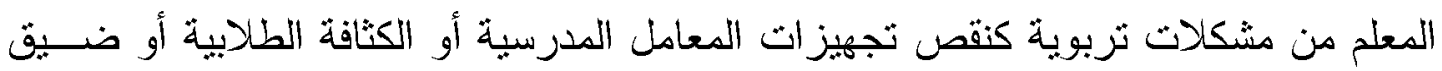

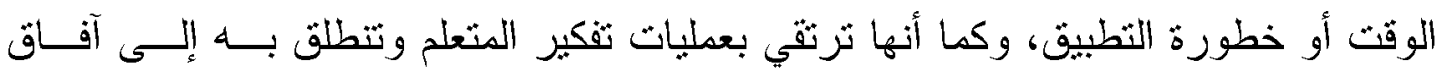
إبداعية لبس لها حدود مكانية أو زمانية.

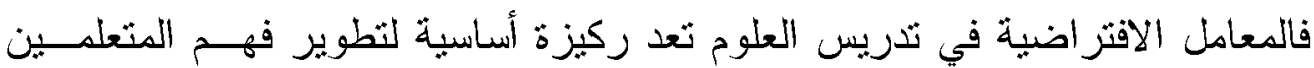

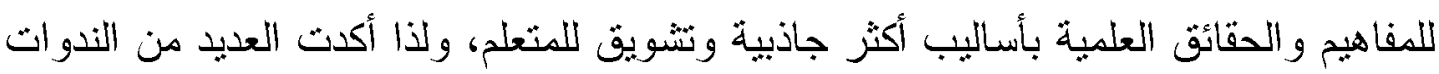

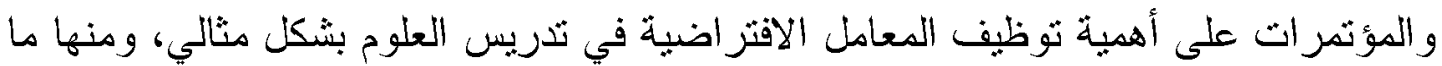

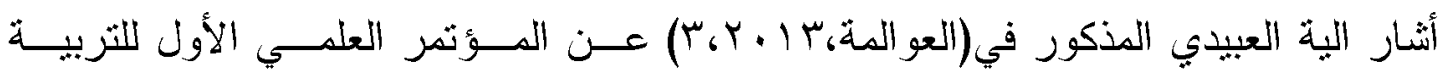

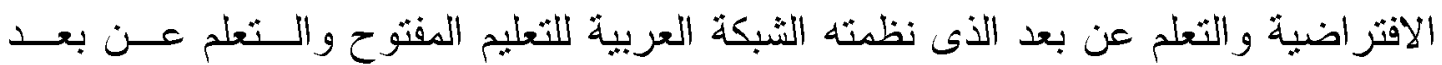




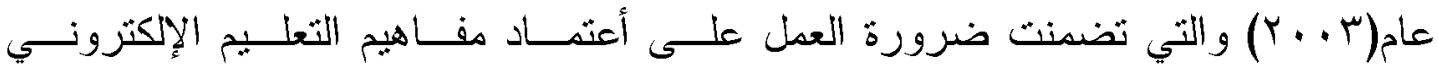

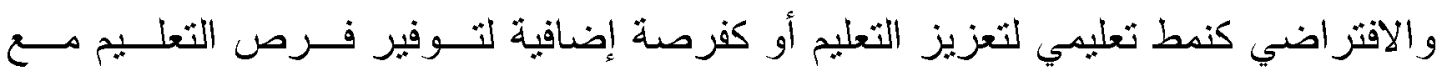

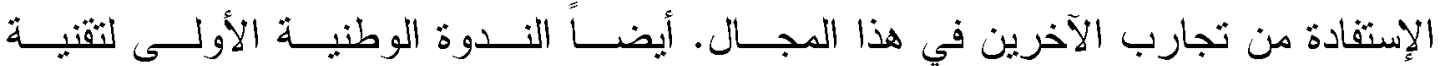

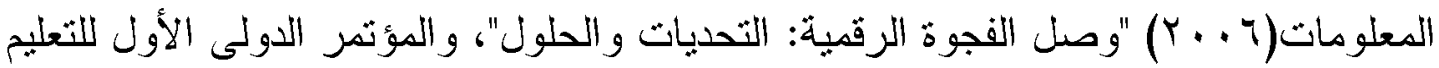

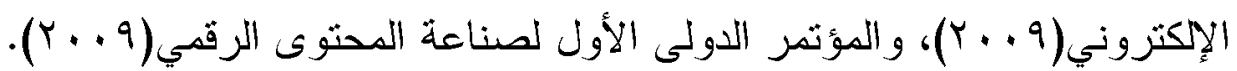

\section{أنواع المعامل الافتراضية:}

تعد ثقنية إستخدام المعامل الافتراضية في تثريس العلوم من أهم الثقنبات الثي أثنتت

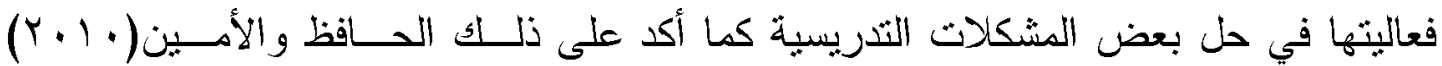

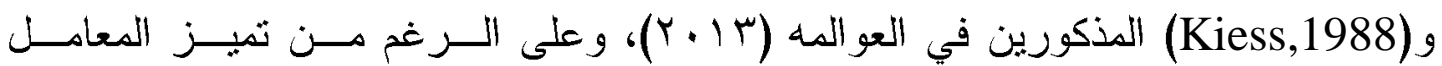

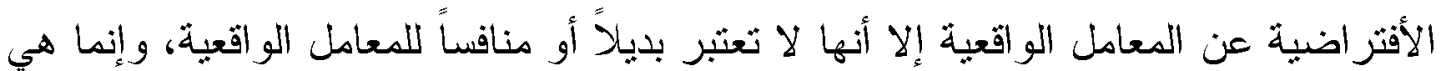

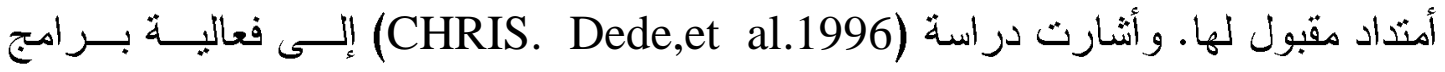

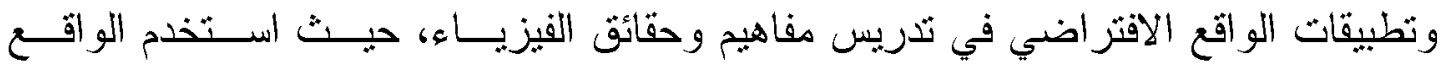

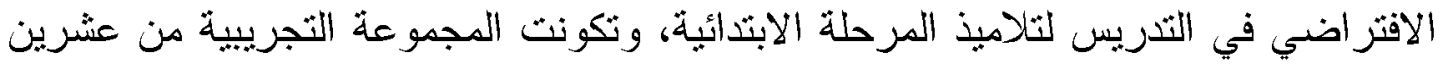

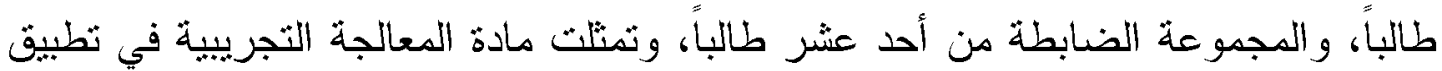

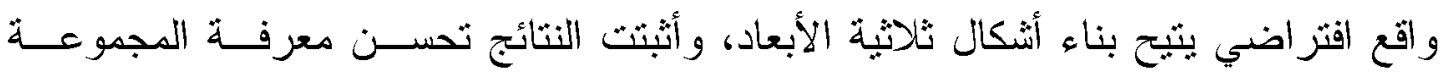
التجريبية التي درست باستخدام الواقع الافتراضي.

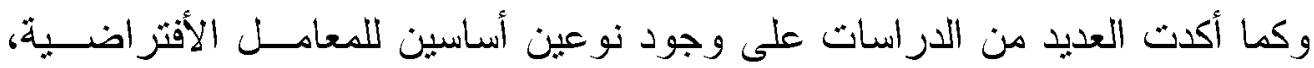

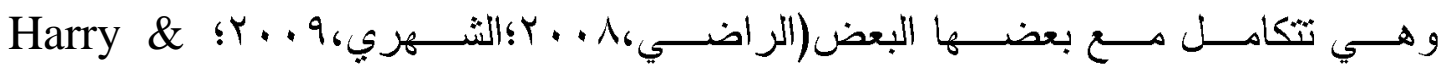

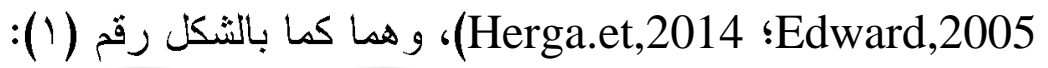

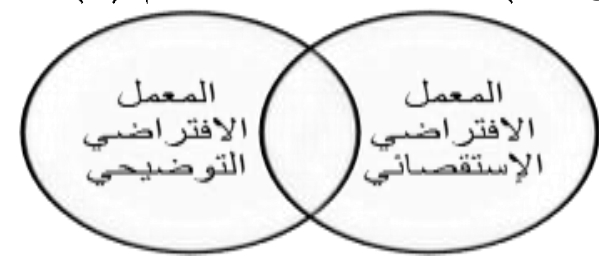

شكل رقم (1) - (1)

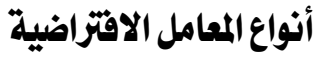

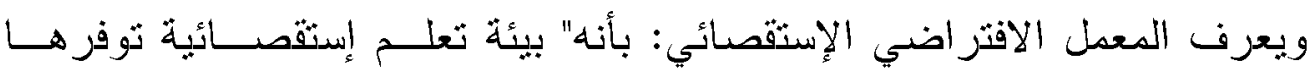

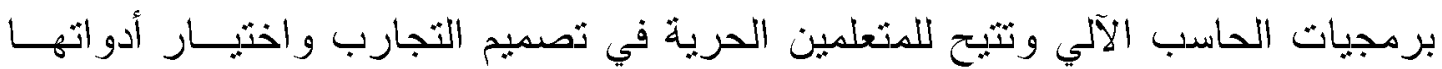

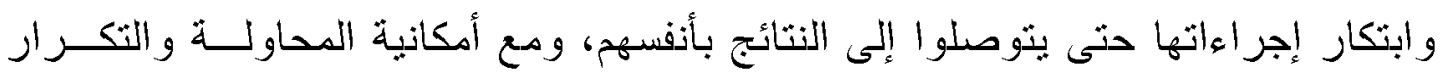


بدون التعرض لأدنى مخاطرة، وبأقل جهد وتكلفة همكنة. وكما بعرف المعدل الافتراضي

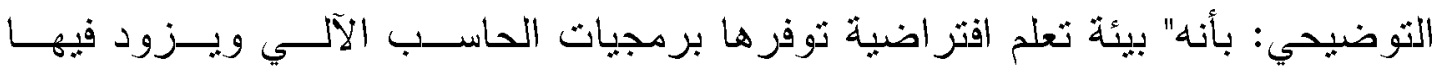

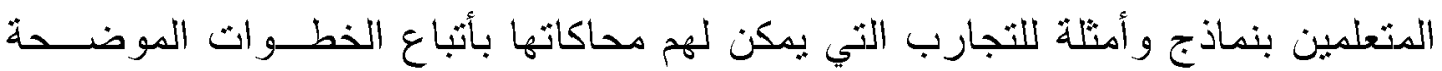

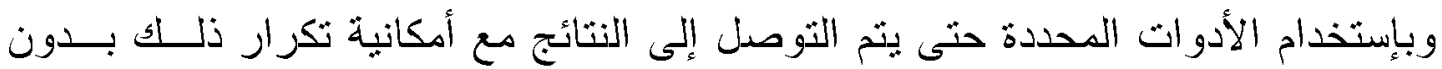

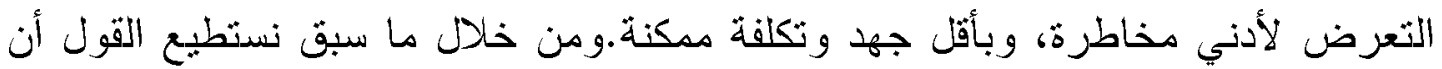

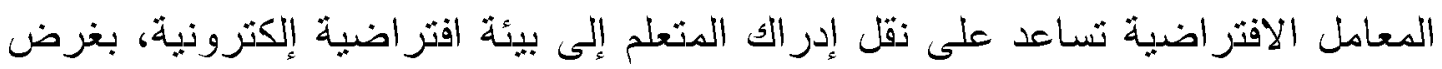
معايشة الأحداث الجارية داخل البرمجية وكأنها حقيقية.

\section{أهمية المعامل الافتراضية في تدريس العلوم:}

ينطلب نعليم الطلبة وتثريبهج على المعامل الافتراضية في تدريس العلوم الــربط بـين

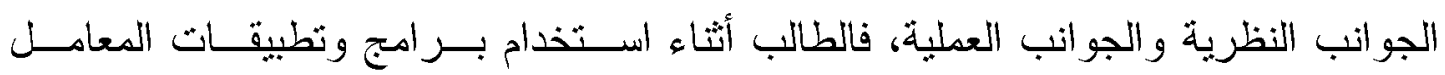

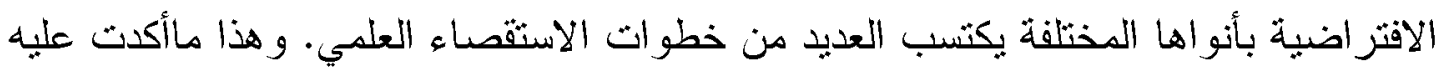

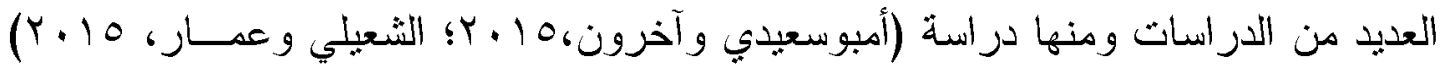

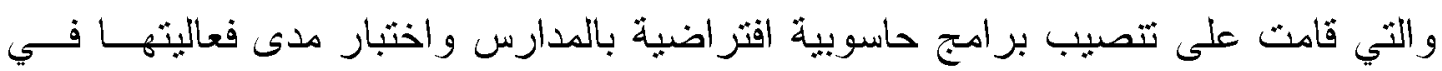
تحقيق فروق دالة إحصائياً على المجموعات التجريبية، وأثنارت نتائجهما إلى أهمية تـأثنير

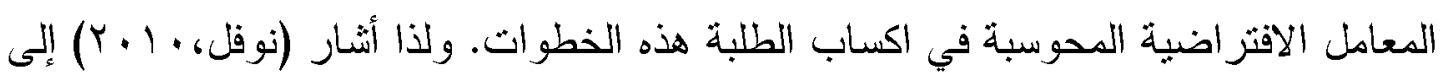

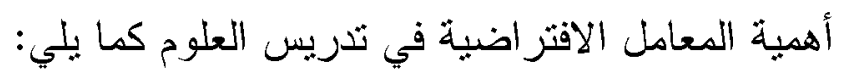

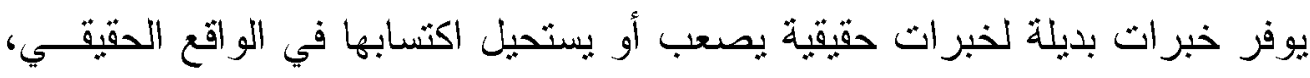

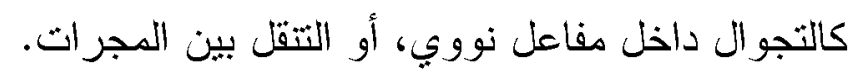

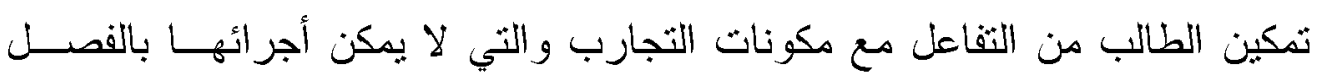

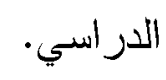

تحقق المعامل الافتزر اضبة التشويق والتحفيز لعملية التعلم.

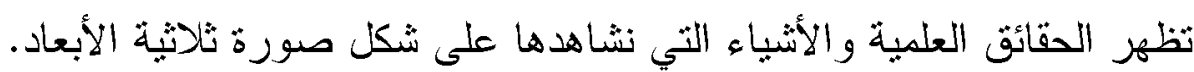

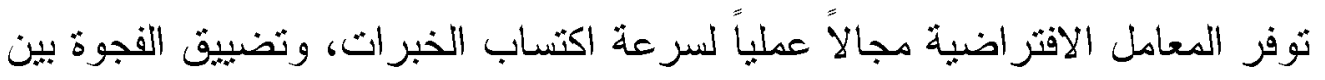

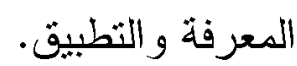

\section{مميزات استخداه المعامل الافتزاضية على تنمية مهارات التعلم الاستقصائي :}

أنثار عدد من الباحثثن إلى مميزات استخدام المعامل الافتزراضية على تتمية مهــارات

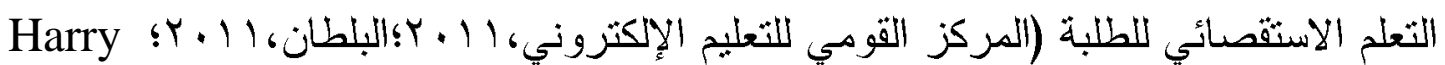




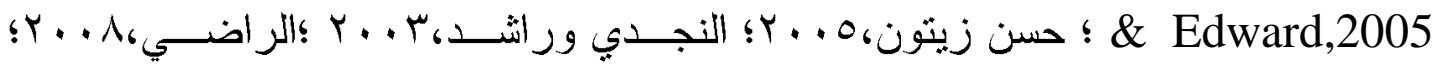
نوفل، • ( • ب؛)، ويلخصها الباحث كما يآتي: تتمية مهارات الطلبة في المهار ات الاستقصائية المختلفة. تكسبهم مهار ات تنفيذ العديد من التجارب الصعبة والخطرة بشكل افتزراضي. تساعدهم في دقة أثبات صدق المعلومات و المعارف العلمية.

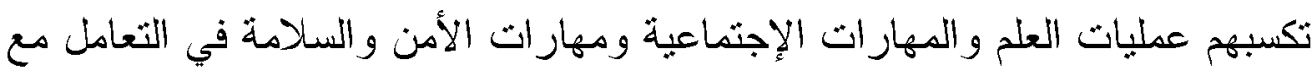

$$
\text { التجارب المختلفة. }
$$

تتمي لايهم مهار ات التفكير العلمي وتساعدهم على التتبؤ بالمشكلة وتحديدها وفرض الفروض وأختبار ها. تنساعدهم على عرض بعض الظواهر و التي لا بمكن عرضها من خــلال التجــارب الحقيقية. هتمي لديهم المهار ات اليدوية، ونتيح لهم فرص جيدة للإبداع والأبنكار .

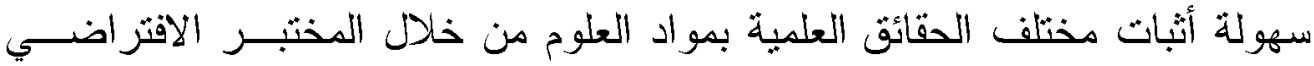

$$
\text { المحاكي للو اقع. }
$$

تعد المعامل الافتراضية من أكثر الطرق الحديثة فعالية فـي التحصـيل الدراسـي

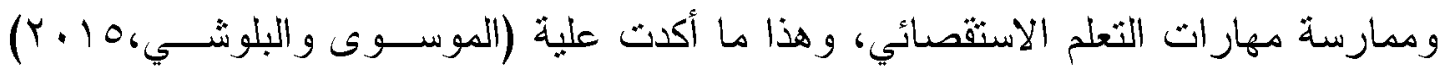

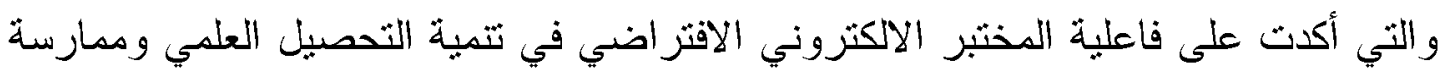

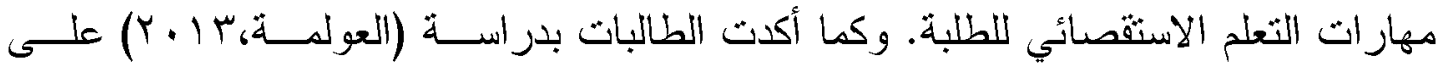
ملاءمة استخدام المعامل الافتراضية في تدريس العلوم لاحتباجــاتهن التربويسـة والمعرفيــة

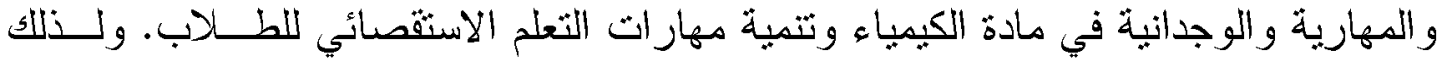
يرى الباحث من خلال ما سبق والرجـوع علــلأدب التربــوي (Slavko \& Colm,2004؛

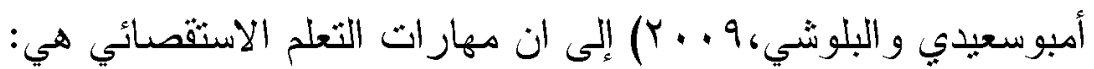

$$
\begin{aligned}
& \text { ا-تجهيز وتوزيع أدوات المواد. } \\
& \text { r- طرح السؤال الاستقصائي. } \\
& \text { ب- تصديم التجربة. } \\
& \text { ـ - تصميم جدول الاستقصاء. }
\end{aligned}
$$

$$
\text { ○-التنبؤُ }
$$

צ- تنفيذ التجربة وتسجيل الملاحظات. 


$$
\begin{aligned}
& \text { V- إنحويل البيانات. } \\
& \text { ᄉ- استخلاص النتائج. } \\
& \text { 9-قنقيم التفسيرات. } \\
& \text { • 1-المقارنة بين الملاحظات و التتبؤات. }
\end{aligned}
$$

لذلك مما سبق تتضح اهمية الدراسة الحالية في تقصي أثر المعامل الافتراضية على الفي ممارسة الطلاب ليهارات التعلم الاستقصائية أثثاء دمارستهم للاروس العملية.

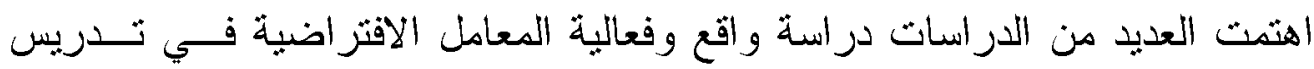

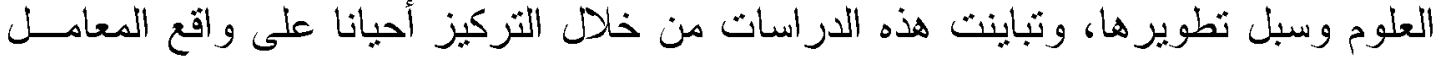

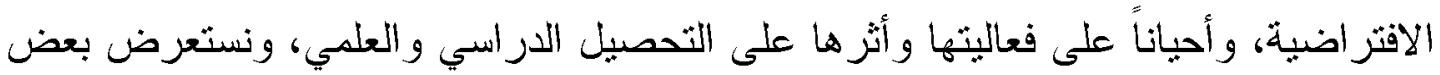

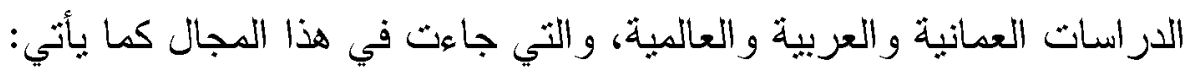

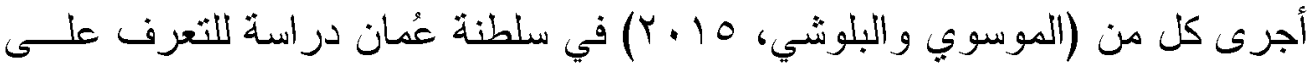

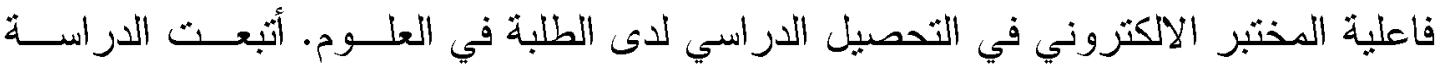

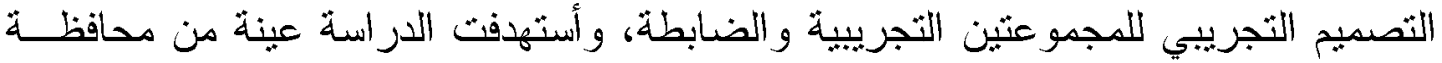

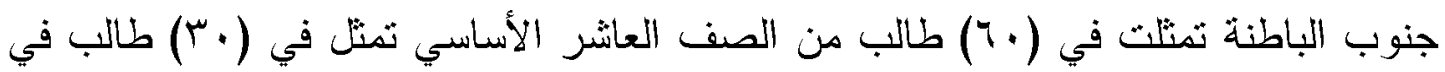

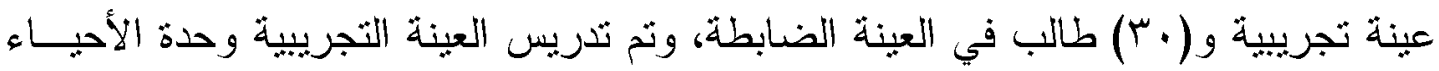

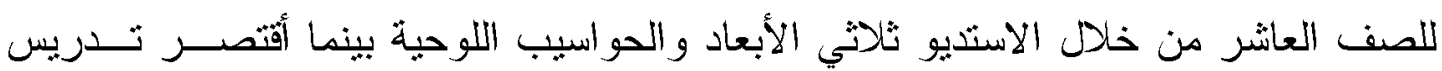
العينة الضابطة على الطرق التقليدية، وتم عرض النتائج والتوصيات بما بعود بالفائدة على الإبى توظيف المختبر الاكتروني في تدريس العلوم مستقبلا في المدارس.

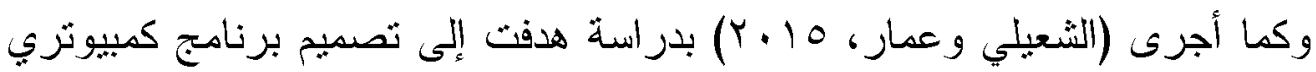

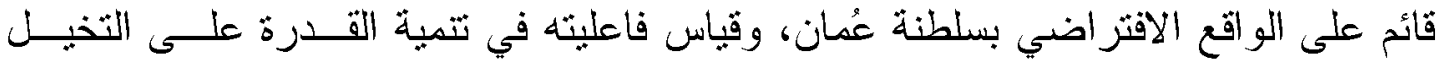

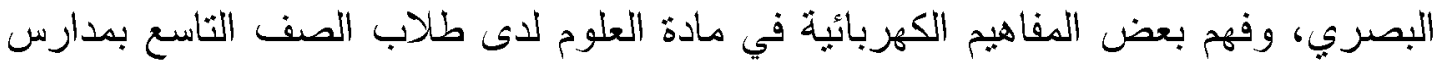

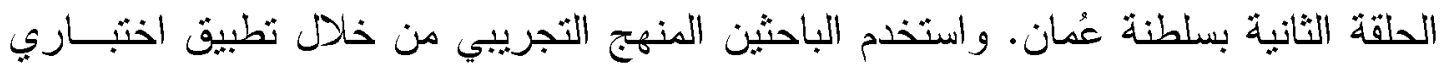

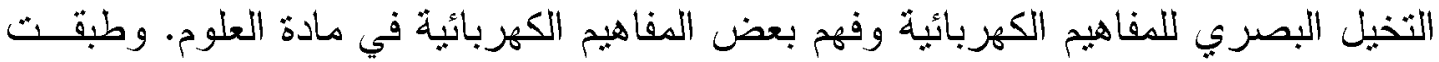

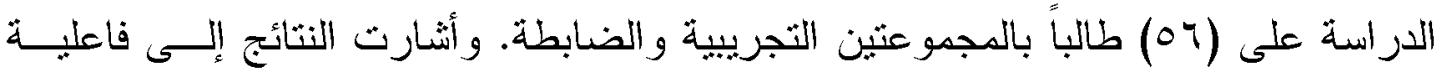

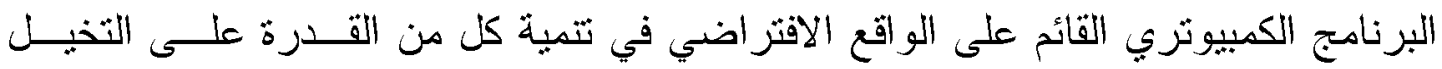

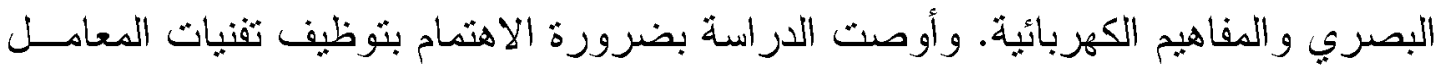
الافتراضية في تدريس العلوم وتدريب المعلمين على مهار ات استخدامها. 
وأجرى (أمبوسغيدي و آخرون ، 10 ب ب) بدراسة ممولة من مجلس البحث العماني حاولت

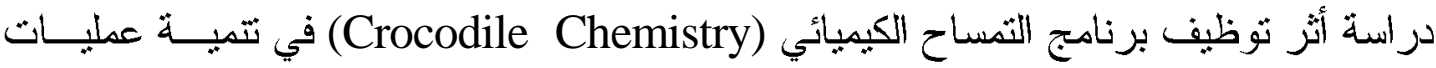

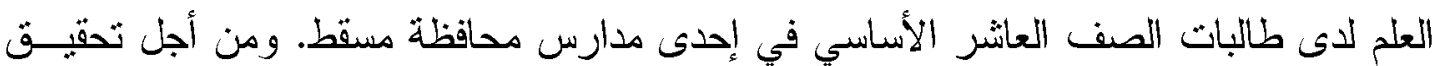

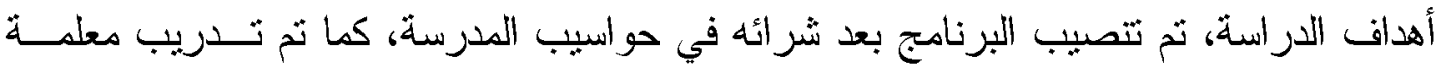

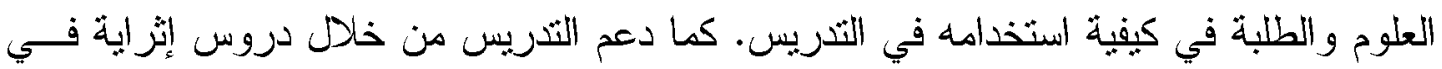

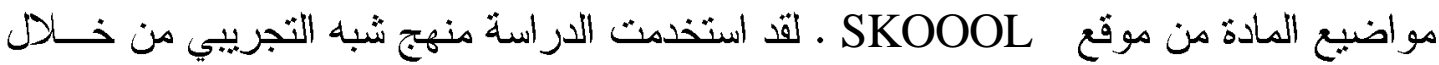

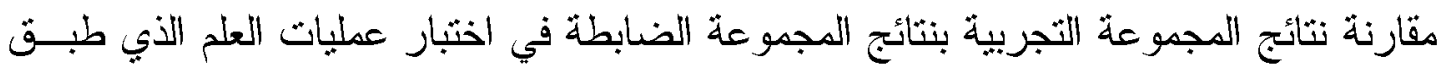

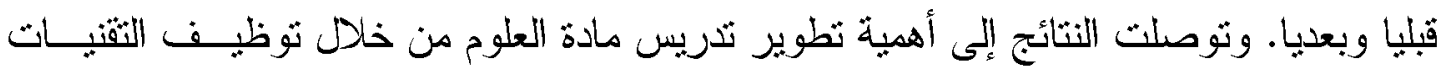
الحيثة، ومنها بالطبع برنامج التمساح الكيميائي (Crocodile Chemistry).

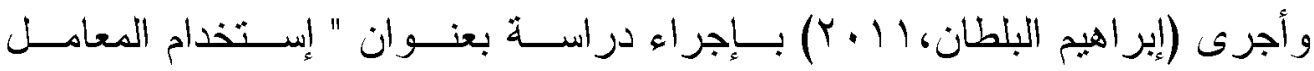
الافتراضية في تدريس العلوم بالمرحلة الثانوية بالمملكة العربية السعودية- الواقـئ وسـبل التطوير"، وأستخدم الباحث المنهج الوصفي المسحي لتحقيق أهداف هذه الدراسة، ولذا نكونت بالنه

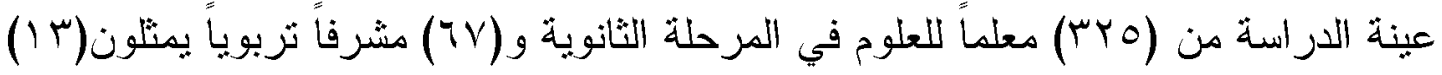

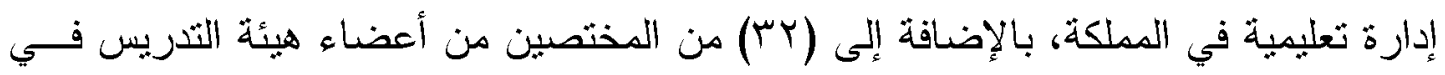

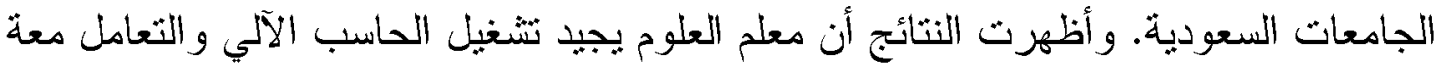
بدرجة كبيرة، ويدرك ماهية المعمل الافتراضي بدرجة منوسطة، وكما بجيد إستخدام المعامل

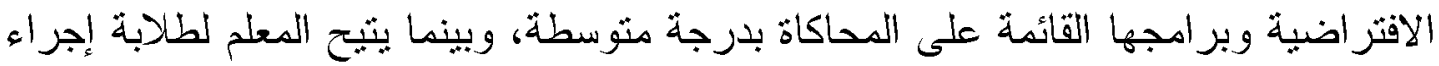
التجارب بدرجة قلبلة. وأجرى كلاً من (Tatli \& Ayas,2011) دراسة هدفت لدراسة مدى نأثنير مختبــر

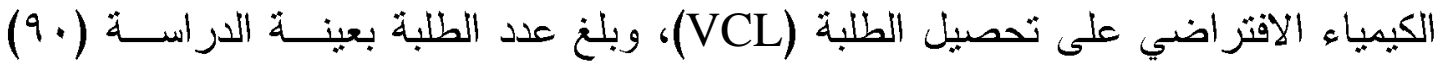

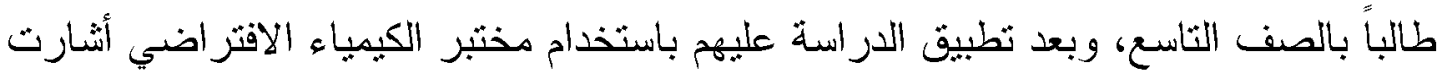

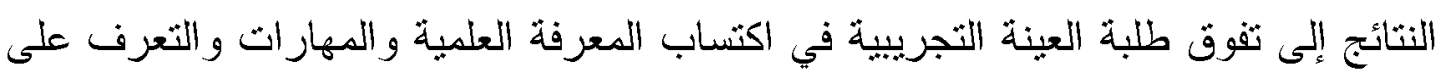

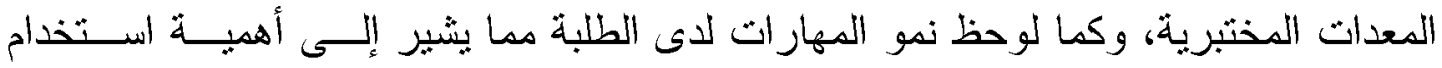

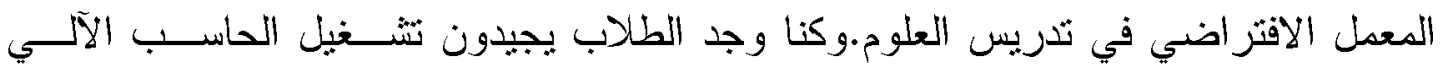

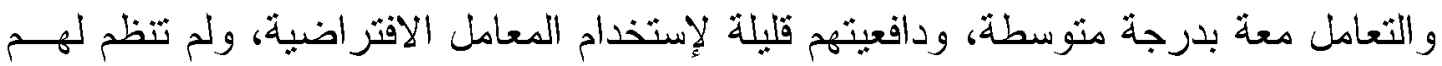

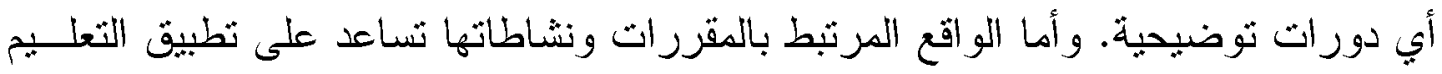


الإكتروني بدرجة متوسطة، وتوفر روابط افتراضية بدرجة قلبلة. وأنشادت الدراسة بوجـود

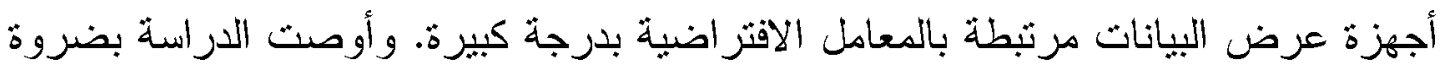
توفير المعامل الافتراضية لأهميثها في تتمبة المهار اتهات الاستقصائية للطلبة.

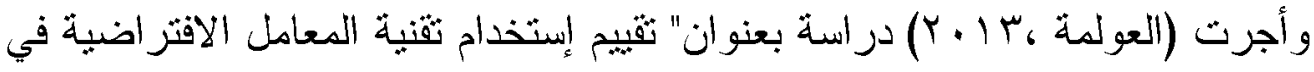
تدريس الكبمباء بالددارس الثانوية بمدنبة الرياض. ولتحقيق أهداف الدراسة قامــت الباحثــة

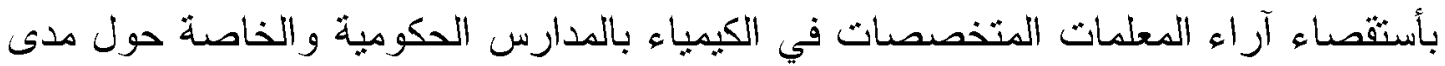

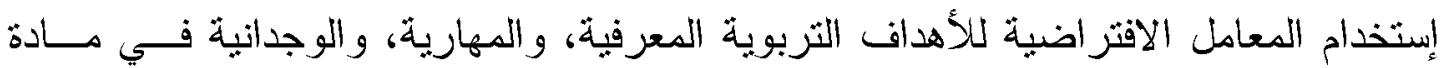
الكيمباء للطالبات بالمدارس الثانوية من جانب، وإستقصاء آراء الطالبات حول مدى ملاءمة إسنخدام المعامل الافتراضبة لإحتباجاتهن التربوية المعرفية والمهارية والوجدانية في هـادة

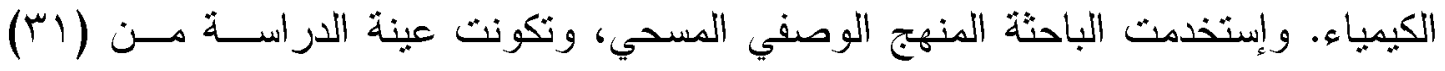

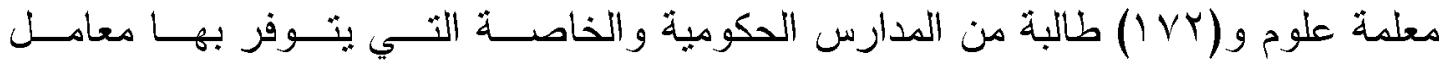

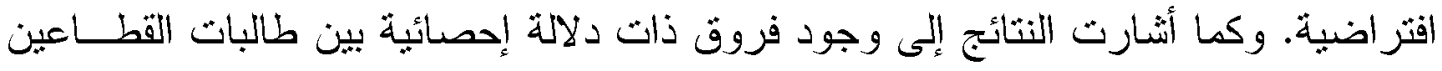
في تقييمهن لمدى تحقيق إستخدام المعامل الافتراضية لاحتباجاتهن التربوية في مادة الكية الكبمياء

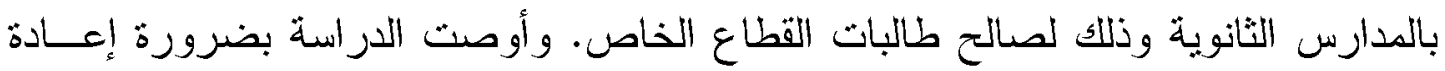

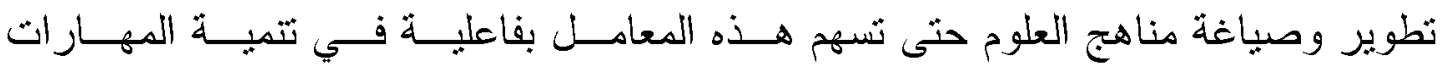
الاستقصائية للطلبة.

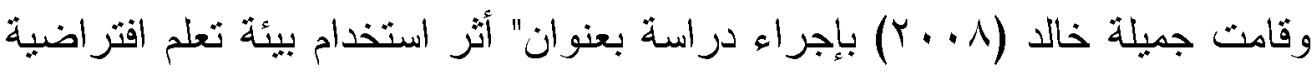

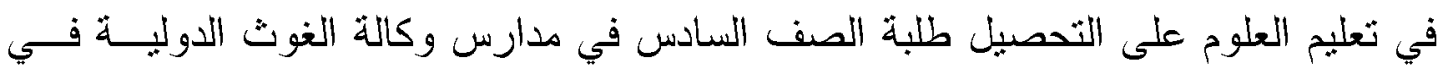

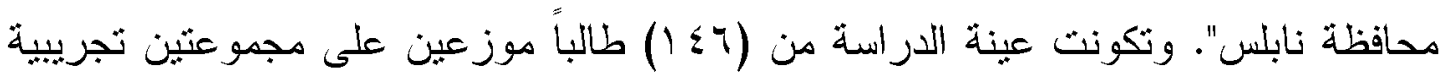

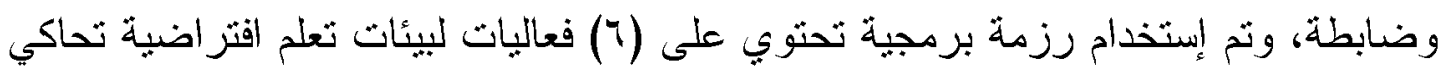

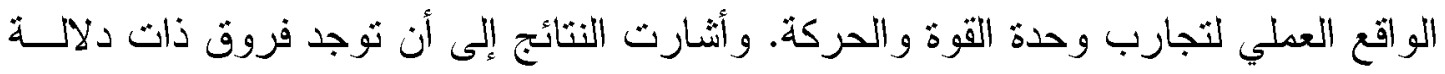

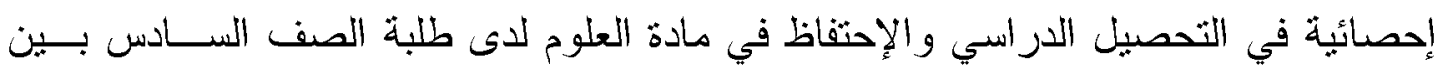

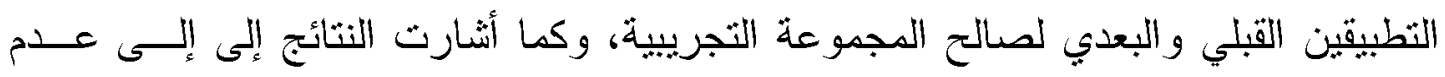

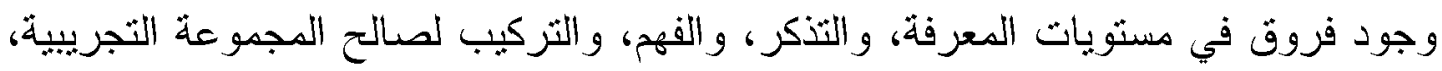

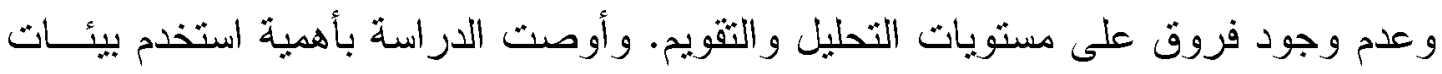

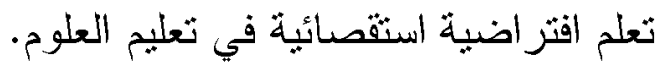




\section{التعقيب على الدراسات السابقة الواردة بالإطار النظري:}

من خلال استعر اض الدراسات السابقة المتعلقة بالمعامل الاففز اضبية فـي تـدريس تجارب الكيمياء، يعقب عليها الباحث كما يلي:

الهنمت عدد من الار اسات العمانية بدر اسة فعالية المعامل الافتر اضــبـة أو المختبـر الإكثروني على التحصيل العلمي و الدراسي للطلبة وتتمية بعض القدرات، ومن هذه الدراسات (الموسوى و البلوشي، 10 • ب) و التي ركزت على منغير التحصيل الدراسي، ودر اسة (الثعيلي وعمار، 0 . ب) و التي ركزت على متغير تتمية القدرة على التخيل البصري، ودر اسة (أمبوسعيدي و آخرون، 10 ب و) والتي ركزت على منغير عمليات العلم، ولذلك ركزت هذه الدراسة على ملاحظة و ثقييم درجة ممارسة الطلبة لمهار ات

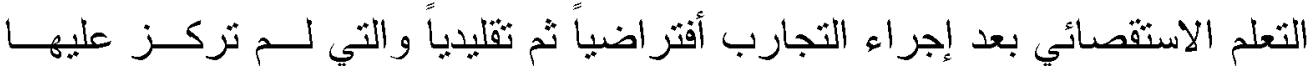

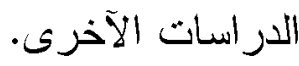

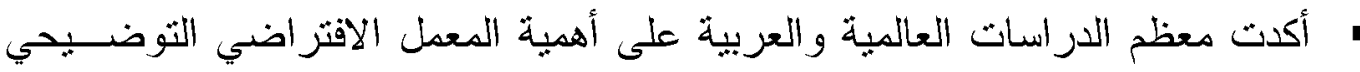

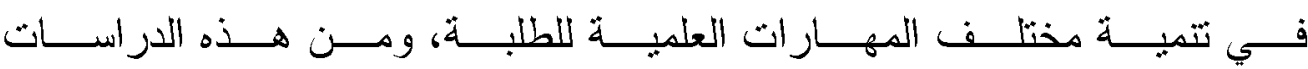

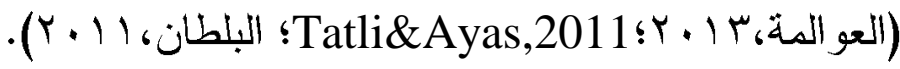

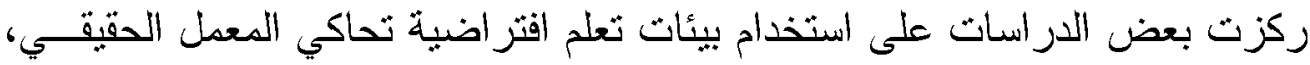

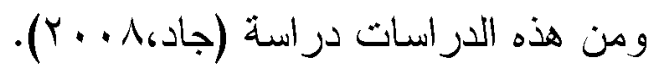

• أستفاد الباحث من الدراسات السابقة في الإطار النظري وإعداد أداة الدراسة وتحليل النتائج و تقسير ها.

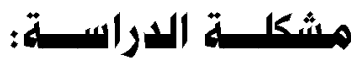

ان نطور العالم الثقني في مختلف العلوم يشكل حثما ثطور كافة الثثنيات الداعمة لعمليـة التعلم، ومعامل العلوم الافتر اضية هي جزء من هذا التطــور . ولــذلك فاســتخدام المعامـلـل

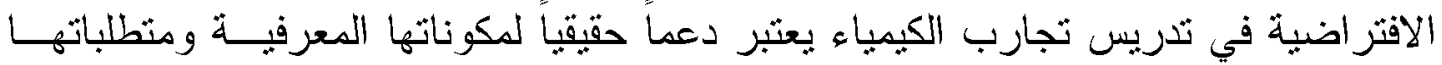

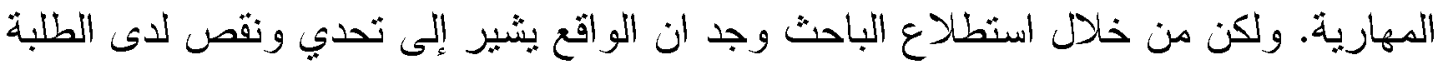

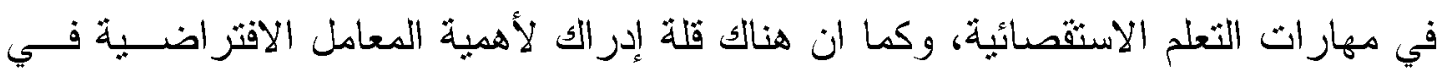

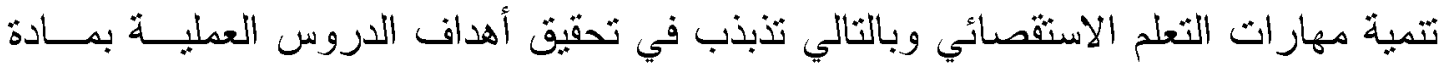

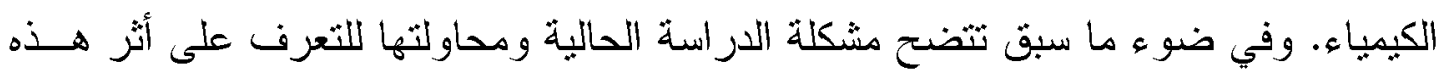

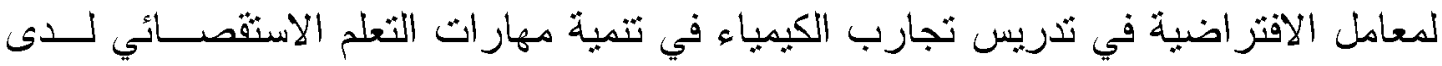
طلاب الصف الحادي عشر بسلطنة عُمان. 


$$
\text { ولذلك تحددت مشكلة الدراسة بالتساؤل الآتي: }
$$

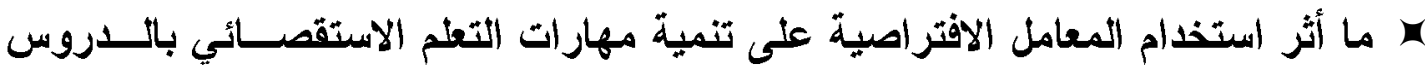

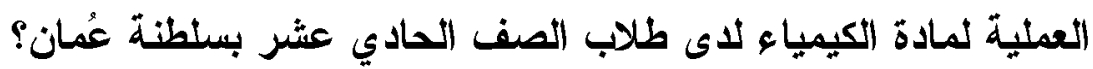

\section{فرضيسات الدراسـتة:}

1- ثوجد فروق ذو دلالة إحصائية عند مسنوى(م =0 . ، ·) بين منوسـطات درجـات

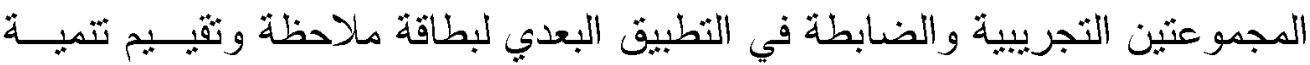
بهار ات التعلم الاستقصائي لصالح المجموعة التجريبية.

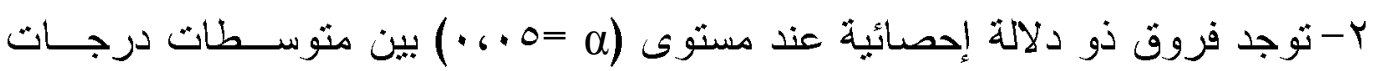

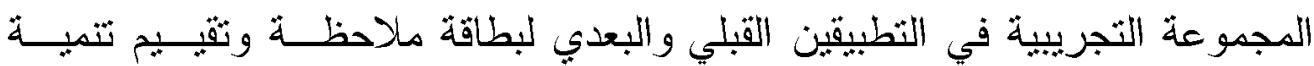
مهارات التعلم الاستقصائي لصالح النطبيق البعدي.

\section{أهـافاف الدراسيسة:}

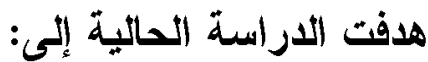

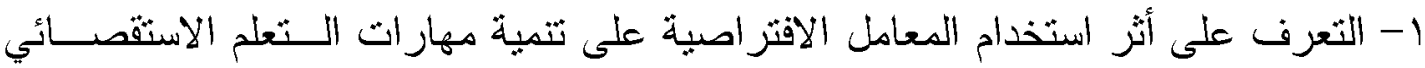

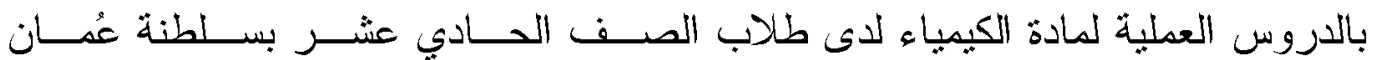

$$
\text { بالمجمو عتين الثجريبية والضابطة. }
$$

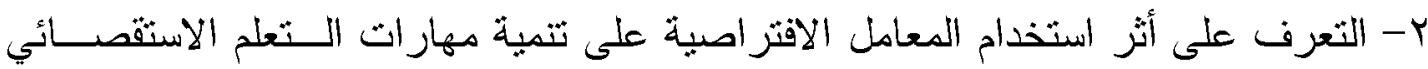

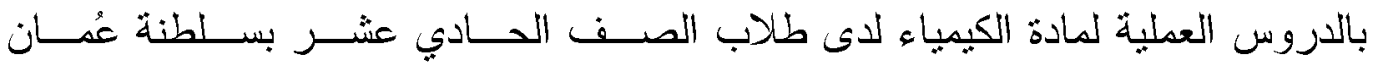
بالمجمو عة التجريبية قبلباً وبعدياً.

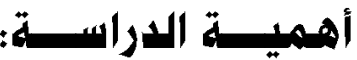

تمثثت أهمية الاراسة الحالية في النقاط الآتية:

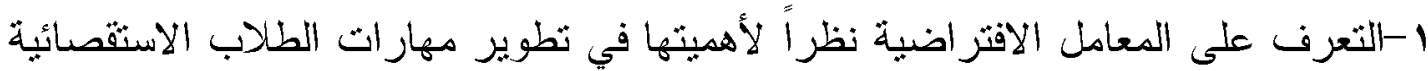
في إجراء التجارب بدقة من خلال تتمبة مهار ات التعلم الاستقصائي لديهم.

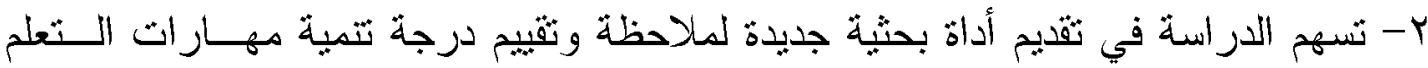

الاسنقصائي لاى الطلاب أنثاء إجر ائه لتجارب الكيمباء باستخدام المعامل الافتزر اضية.

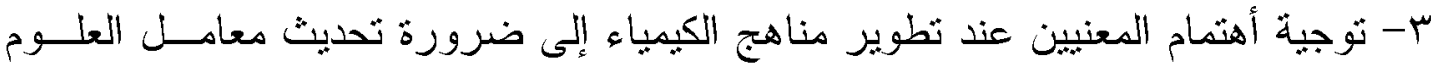
و الكيمياء بما يتتاسب مع بيئات المحاكاة الافتراضية المعملية. 


\section{حسدود الثراسبة}

\section{تحددت حدود هذه الار اسة بالحدود الآتية:}

1- تحددث الحدود الموضوعية بالدر اسة في التعرف على أثز المعامل الافتز اضــبة على الـى تتمية مهار ات التعلم الاستقصائي في (· ( ) مهار ات رئيسية، و (ب) مهارة فرعية. r- تحددت البشرية والحدود المكانية بتطبيق الدراسة على طلاب الصف الحــادي بإحــدى

$$
\text { مدارس الأكور بمحافظة جنوب الباطنة فقط. }
$$

ب- تحددت الحدود الزمانية في إجراء الدراسة الميدانية وتطبيق بطاقة الملاحظــة و الثمبــيم

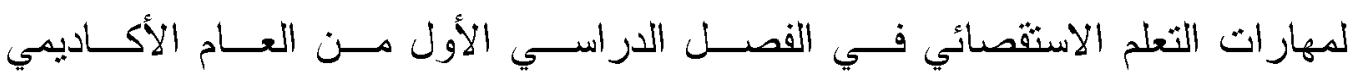

$$
\cdot \hat{r} \cdot 1 T / r \cdot 10
$$

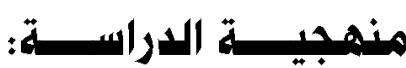

ثم استخدام المنهج شبه التجريبي القائم على تصميجم المجوعثين الضابطة والتجريبيـة و القائم على القباس القبلي والبعدي لملاحظة أثر المعامل الافتر اضية على تنميـة مهــار ات التعلم الاسثقصائي للطلاب، حيث أجرث المجموعة التجريبية التجارب باســتخدام المعدـلـ الافتر اضي، ويينما المجموعة الضـابطة أجرت التجارب بالدروس العملية بالطريقة العمليـة التقليدية.

\section{هصطاد هـات الدراســة}

\section{المعامل الاقتراضيةه}

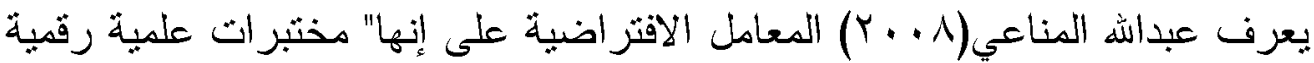
مناسبة ووسائل الاتصـال بالثبكة العالمبة تمكن المعلم من القبام بالتجارب العلمبـة الرقيــة

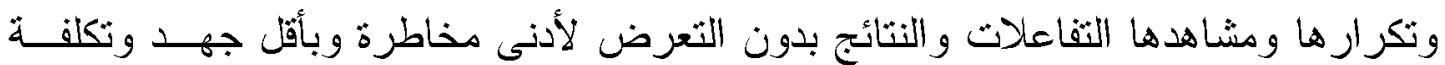

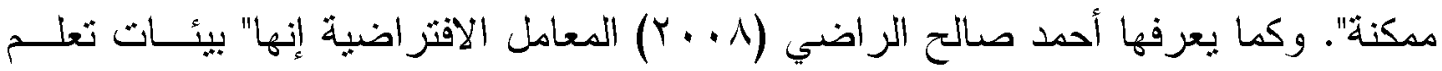

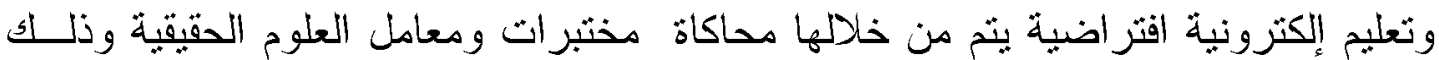
بتطبيق التجارب العملية بشكل افتز اضي يحاكي التطبيقي الحقيقي، وتكون متاحة للإِـــتخدام من خلال الأقر اص المدمجة، أو من موقع شبكة الأنترنت".

\section{مهارات التعلم الاستقصائي:}

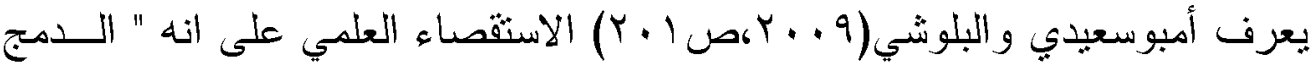
بين عمليات العلم والمعرفة العلمية واستخدام التفكير النقدي والإستدلال العلمي بهـدف بنــاء 
الفهم العلمي". ويعرف الباحث مهارات التعلم الاستقصائية إجر ائياً على أنها الخطوات التـي

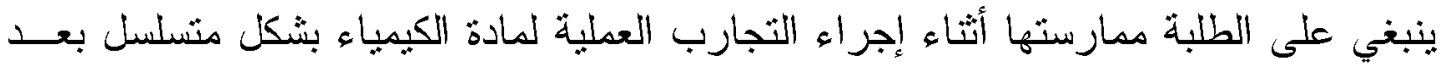

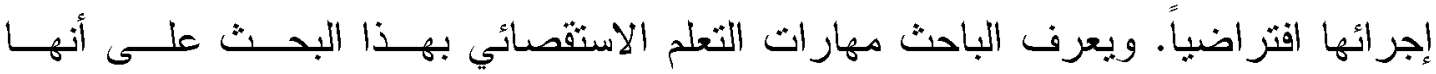

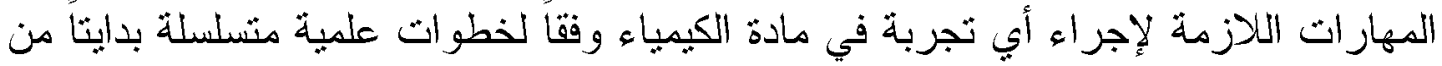

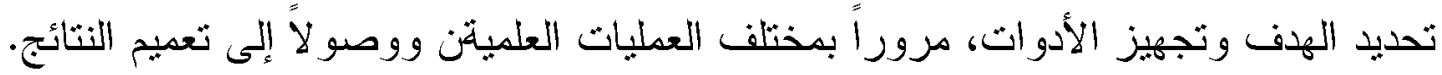
لذلكك يعرف الباحث إجرائيساً نتمبة مهار ات التعلم الاستقصائي بالدروس العملية لمادة

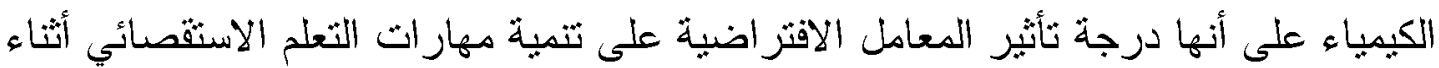

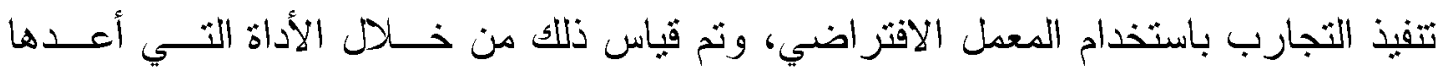
الباحث لأغر اض هذه الدراسة.

\section{إجراءات وأدوات الدراسة:}

أولاً : مجتمع الدراسة :

تكون مجتمع الدراسة من جميع طلاب الصف الحادي عشر بمحافظة جنوب الباطنة

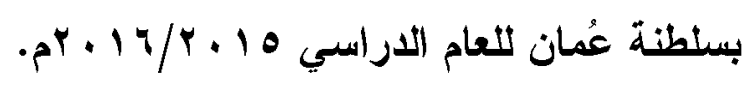

\section{ثانياً : عينة الدراسة:}

تم اختيار عينة ممثلة لمجتمع الدراسة من خلال اختيار أحد مدارس جنوب الباطنه،

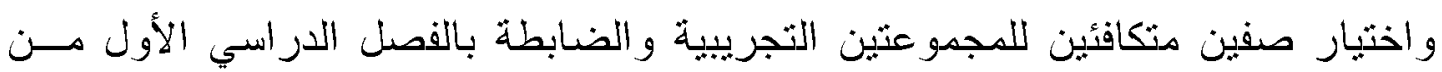

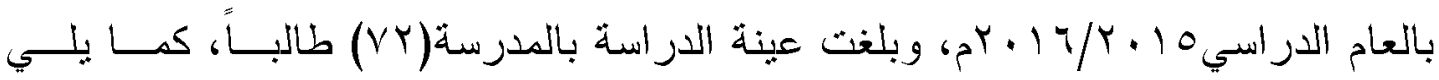

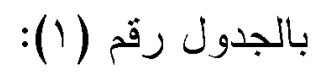

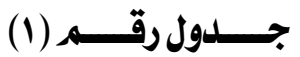

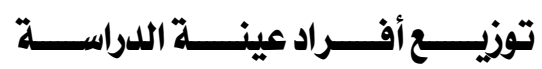

\begin{tabular}{|c|c|c|c|}
\hline مجموع عبنة الدراسة & الضابطة & التجزيبية & نوع المجمو عة \\
\hline Vr & ro & rv & الإجمالي \\
\hline
\end{tabular}

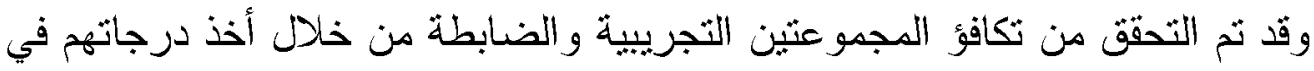

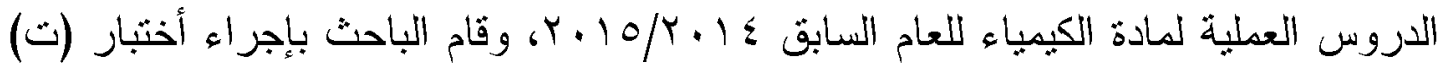

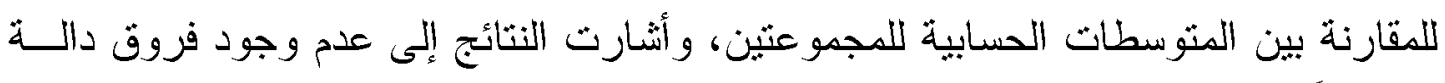

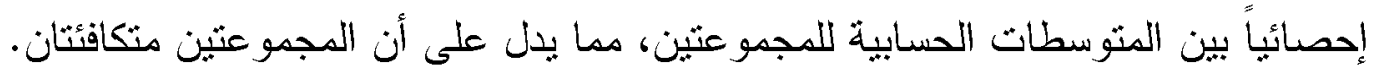




\section{مواد الدراسة وأدواتها:}

\section{اولاً : برنامج Crocodile Chemistry}

قام الباحث باستخدام برنامج (التصساح الكيميائي الافتراضي- Crocodile Chemistry)

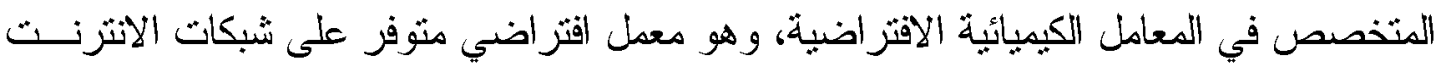

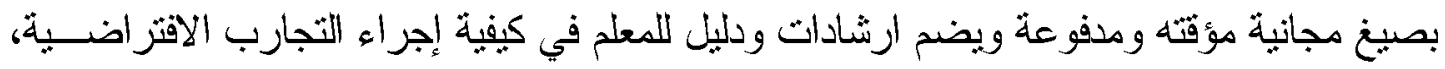

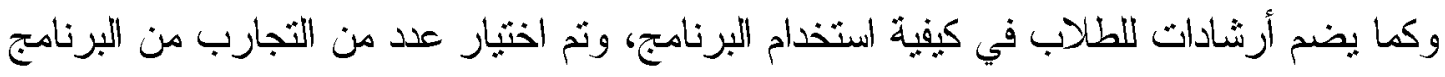

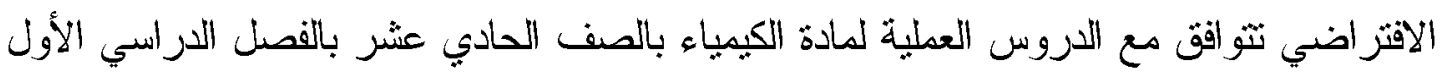

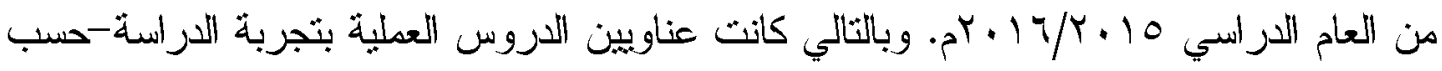

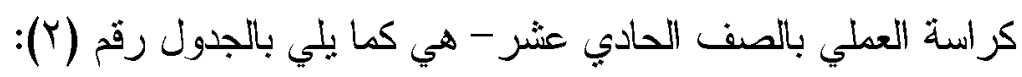

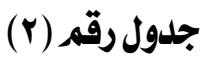

عناويين الدروس العملية من كتاب الكيمياء بالصف الحادي عشر بتجربة الدراسة

\begin{tabular}{|c|c|c|c|c|c|c|c|}
\hline$r$ & 7 & 0 & $\xi$ & $r$ & $r$ & 1 & التسلسل \\
\hline الكحولات & الأحماض & الهواد الروجيني & تمتولين الكتلة متلية غيرة & تحختيل تحتيل & ذمادة صلبية & الجزئيات & العندان \\
\hline
\end{tabular}

\section{ثانياً: بطاقة الملاحظة والتقييم:}

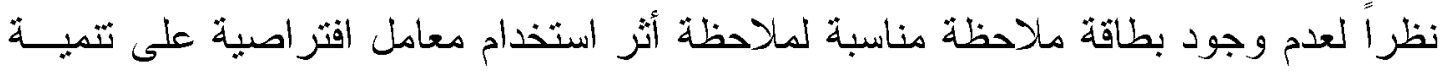

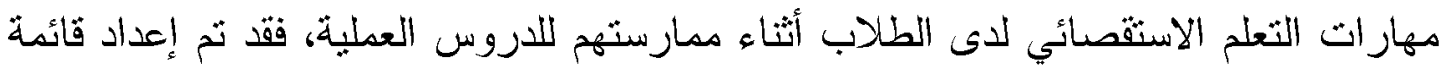

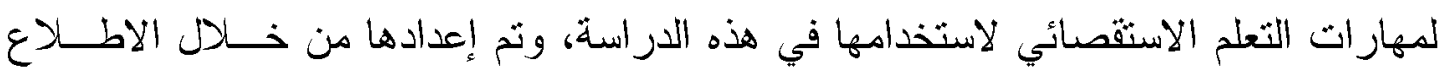

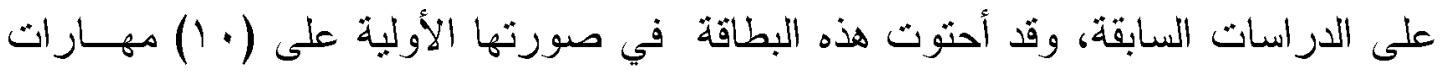

$$
\text { رئيسية وتثضمن (TY) مهارة فرعية. }
$$

\section{ثالثاً : صلدق أداة الدراسة:}

لحساب صدق بطاقة الملاحظة والتقييم أعتمد الباحث على صدق المحكمين، حيث ثم

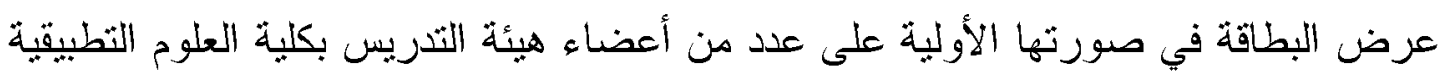

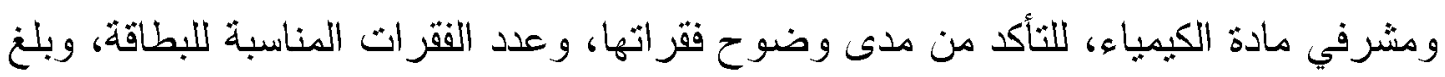

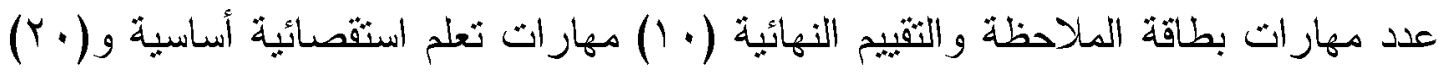

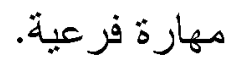




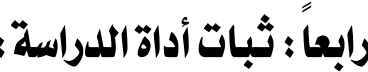

تم حساب ثبات بطاقة الملاحظة والثقييم تنمية مهار ات التعلم الاستقصائي من خلال

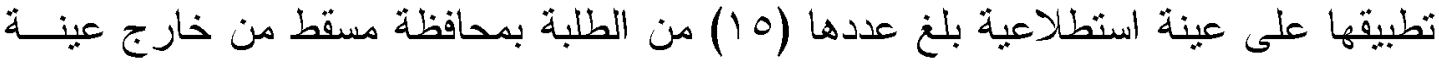

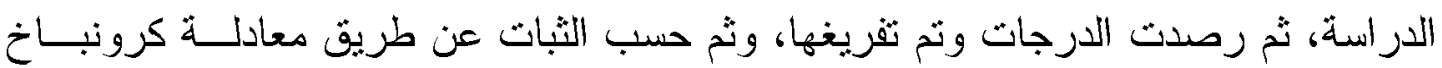

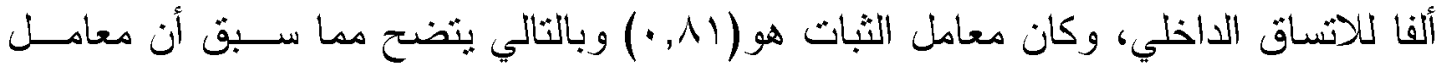

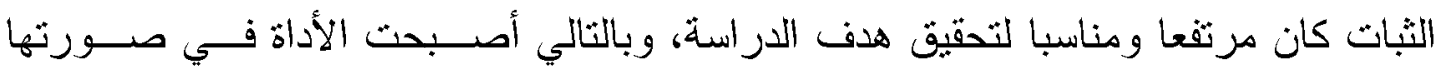

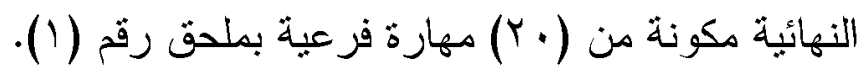

خامساً: تصميم الدراسة ومتفيراتها :

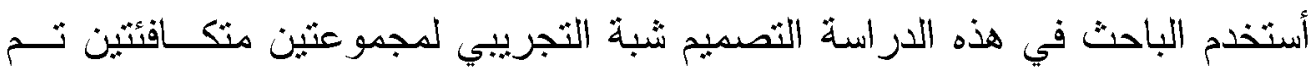
أختيار هم بطريقة قصدية، ولذلك الدراسة تحددت كما يلي:

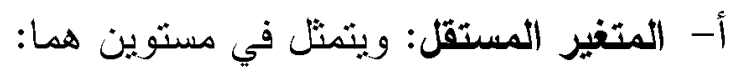
• استخدام معمل افتراضي بالمجموعة التجريبية. • استخدام معمل تقليدي بالمجمو عة الضابطة. ب-المتغير التابع، ويتمثل في: • • درجة تنمية مهار ات التعلم الاستقصائي.

ويوضح الثكل رقم (ץ) التصميم شبة التجريبي للار اسة:

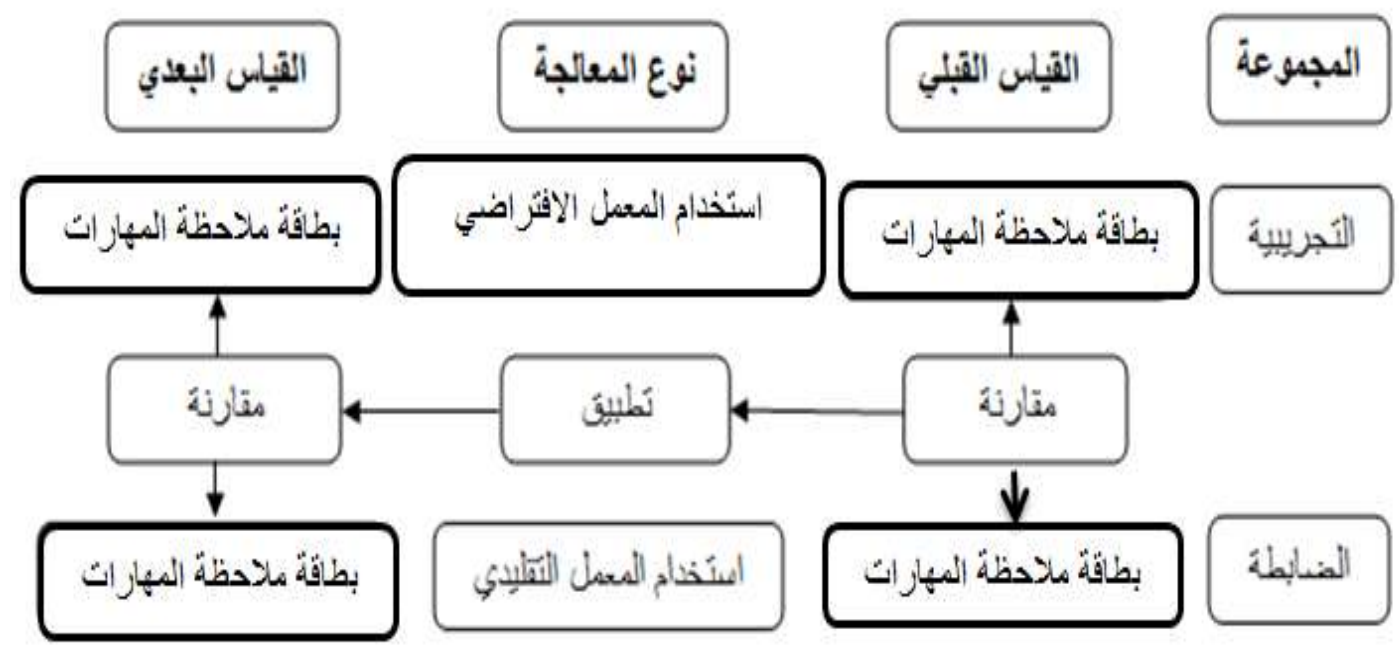

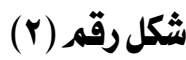

التصميمشبة التجريبي للدراسة 


\section{سابعاً : تطبيق الدراسة:}

قام الباحث بالإجر اءات الآتبة لتطبيق الدراسة:

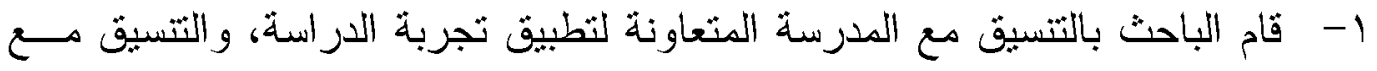
المعلمين المتعاونين لتنفيذ الجانب العملي من الدراسة الدراسة نحت إثراف وتوجية

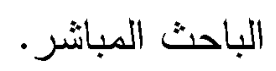

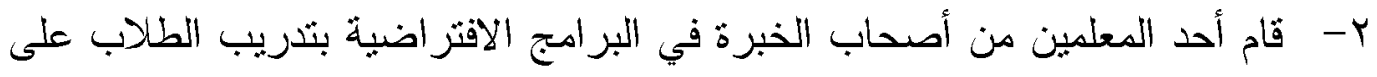

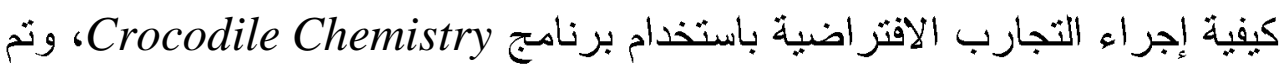

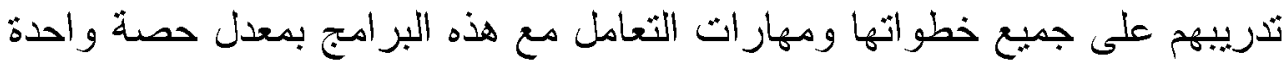
لمدة أسبو عين قبل تجربة الدراسة.

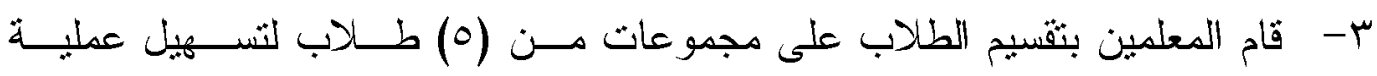

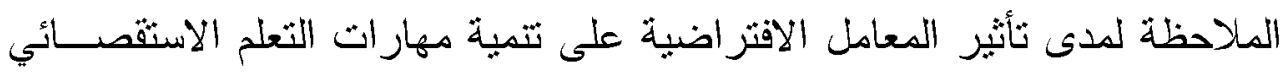
لايهم في المجموعة التجريبية. ـ - قام طلاب المجموعة التجريبية بإجراء تجارب الدروس العملية باستخدام المعدـلـل الافتر اضي، مع مر اقبة المعلمين لدرجة تنمية هذه المعامل لمهار اتهم الاستقصــائية

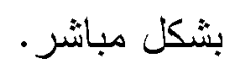

ه- قام الطلاب بالمجموعة الضابطة بإجراء الثجربة فقط بـدوياً باســنخدام المعهـل التقليدي. צ- متابعة المعلمين للطلاب أثناء أدائهم على التجارب بالدروس العملية خطوة خطـــوة وتسجيل النتائج ببطاقة الملاحظة.

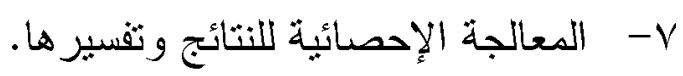

\section{عرض النتائج وتفسيرهـا:}

\section{النتائج المتعلقة بتساؤل الدراسة:}

× ما أثر استخدام المعامل الافتراصبة على تتمية مهارات التعلم الاستقصائي بالدروس

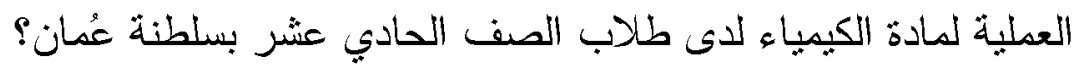
ونم الإجابة عن تساؤل الدراسة من خلال الإجابة عن الفرضيات الآتية: 


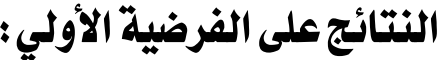

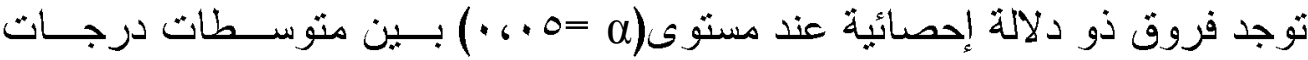

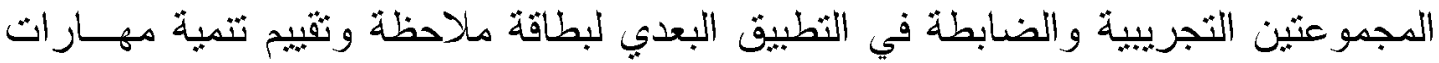

التعلم الاستقصائي لصالح المجموعة التجريبية.

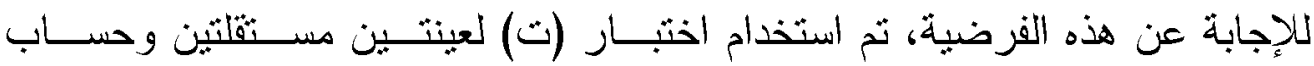

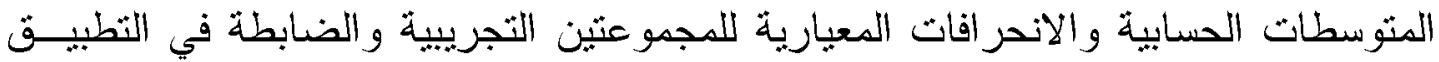

البعدي كما يوضحها جدول رقم (ॅ):

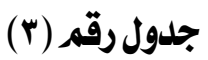

نتائج استخلاه اختبار (ت) لعينتين مستقلتين وحساب المتوسطات الحسابية والانحرافات المعيارية

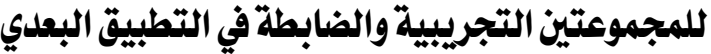

\begin{tabular}{|c|c|c|c|c|c|c|}
\hline مستوى الدلاية & قيمة & الحرية & الالمياري & الحسابي & مهارات التعله الاستقصائي & المجموعة \\
\hline \multirow{2}{*}{$\cdot, r$} & \multirow{2}{*}{$7, r \wedge$} & \multirow[b]{2}{*}{ v. } & 1, rqu & $\xi, \cdot r$ & \multirow{2}{*}{ تجهيز وتوزيع أدوات المواد } & التجريبية \\
\hline & & & $1, r \cdots$ & $r, 90$ & & الضابطة \\
\hline \multirow{2}{*}{$* \bullet, \cdots$} & \multirow{2}{*}{$0, \cdot v$} & \multirow{2}{*}{ v. } & 1,079 & $\xi, \eta r$ & \multirow{2}{*}{ طرح السؤال الاستقصائي } & التجريبية \\
\hline & & & $\cdot$, \&YY & $r, r r$ & & الضابطة \\
\hline \multirow{2}{*}{$* \bullet, \cdots$} & \multirow{2}{*}{$\cdot, 9 \mathrm{~V}$} & \multirow{2}{*}{ v. } & $1,0 . r$ & $\xi, \S 9$ & \multirow{2}{*}{ تصميه التجربة } & التجريبية \\
\hline & & & $\cdot, \wedge \wedge \uparrow$ & $\xi, r \mu$ & & الضابطة \\
\hline \multirow{2}{*}{$\cdot, r \xi$} & \multirow{2}{*}{ 7, rT } & \multirow{2}{*}{ v. } & $1,\{7 \xi$ & $\xi, \$ 7$ & \multirow{2}{*}{ تصميم جدول الاستقصاء } & التجريبية \\
\hline & & & $1, r v$. & $\xi, r r$ & & الضابطة \\
\hline \multirow{2}{*}{$* \bullet, \cdots$} & \multirow{2}{*}{0,19} & \multirow{2}{*}{ v. } & $1,0 \leqslant 9$ & $\$$, ro & \multirow{2}{*}{ 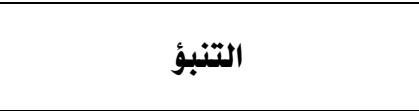 } & التجريبية \\
\hline & & & •, \&\&r & $r, Y 乏$ & & الضابطة \\
\hline \multirow{2}{*}{$* \bullet, \cdots$} & \multirow{2}{*}{$r, r r$} & \multirow{2}{*}{ v. } & 1, rav & r, rA & \multirow{2}{*}{ تنفيذ التجربة وتسجيل الملاحظات } & التجريبية \\
\hline & & & •, AOr & $r, Y$ & & الضابطة \\
\hline \multirow{2}{*}{$* \bullet, \cdots$} & \multirow{2}{*}{$0, r q$} & \multirow{2}{*}{ v. } & $1,0 \leqslant 9$ & $\xi, r Y$ & \multirow{2}{*}{ تحويل البيانات } & التجريبية \\
\hline & & & •, \&\&T & $r, Y 乏$ & & الضابطة \\
\hline \multirow{2}{*}{$* \bullet, \cdots$} & \multirow{2}{*}{$\xi, 0 \wedge$} & \multirow{2}{*}{ ve } & 1,711 & $\xi, \vee \wedge$ & \multirow{2}{*}{ استخلاص النتائج } & التجريبية \\
\hline & & & $\cdot, 0 . r$ & $r, \& 9$ & & الضابطة \\
\hline \multirow{2}{*}{$* \bullet, \cdots$} & \multirow{2}{*}{$1, \wedge \varepsilon$} & $v_{0}$ & $1,0 . r$ & $\xi, \S 9$ & تقت & التجريبية \\
\hline & & 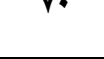 & $\cdot, r \cdot \eta$ & $r, q Y$ & سمديه السقسيرات & الضابطة \\
\hline$* . .$. & 99 & v. & I,VYY & $\xi, Y \xi$ & لمالمانة & التجريبية \\
\hline${ }^{* \bullet}, \cdots$ & $1, \pi$ & 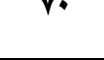 & •, \$\& & $r, Y q$ & المهاريه بيل الملاحطاس وار & الضابطة \\
\hline$* \ldots$ & 0.17 & $v_{0}$ & 10, Yro & $\$ r, \bullet \eta$ & & التجريبية \\
\hline$\cdots, \cdots$ & 0,11 & 16 & $v, r v I$ & To, T\& & שـ & الضابطة \\
\hline
\end{tabular}

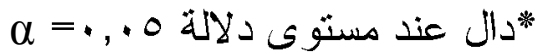


نلاحظ من الجدول السابق رقم (T) ان منوسط أداء المجموعة التجريبية الثي أجرت

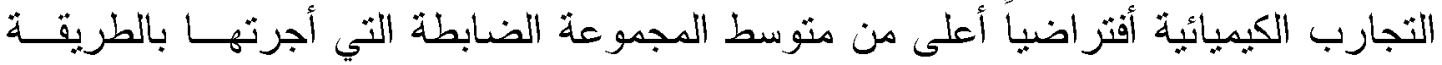

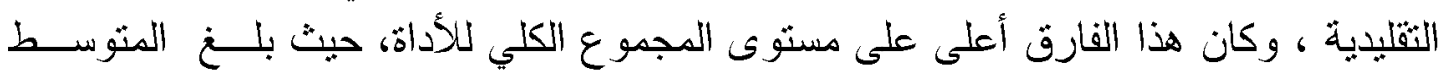

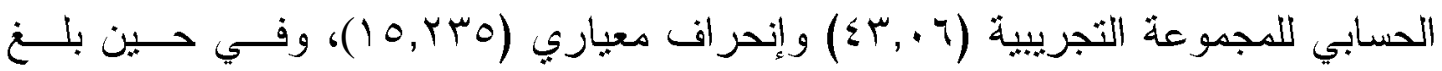
المتوسط الحسابي للمجموعة الضابطة (

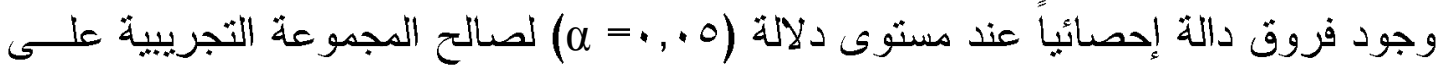

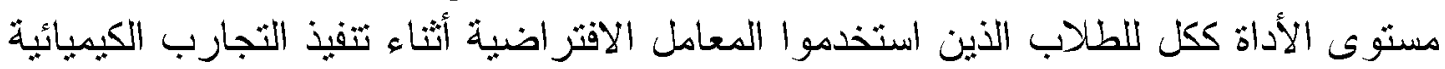

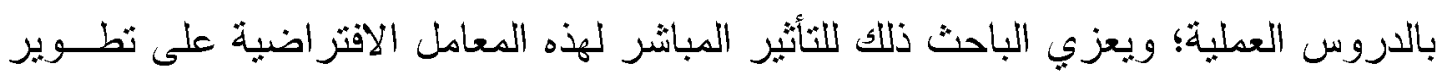
مهار ات الطلاب المعلية وتتمية مهار اتل التعلم الاستقصائية لايهم.

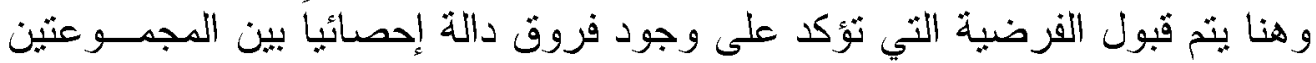

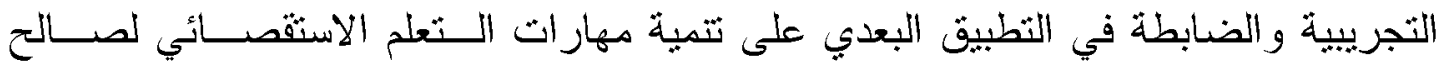

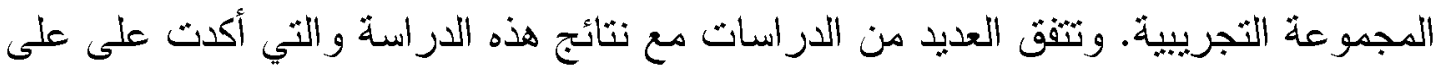

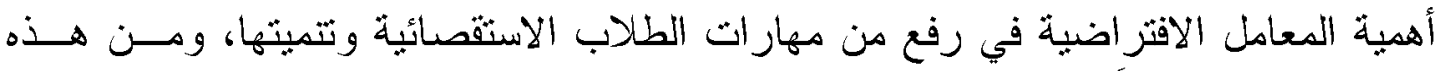

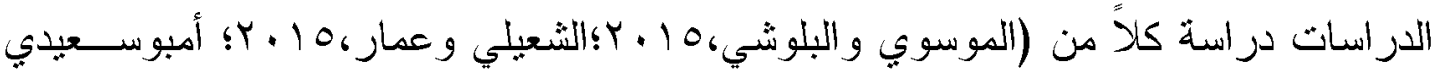

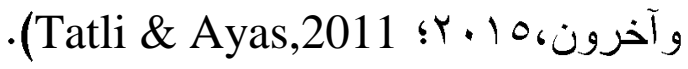

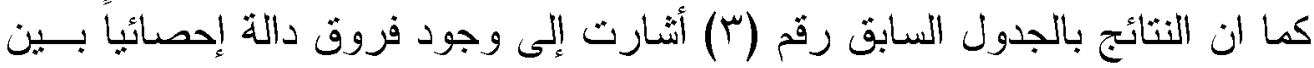

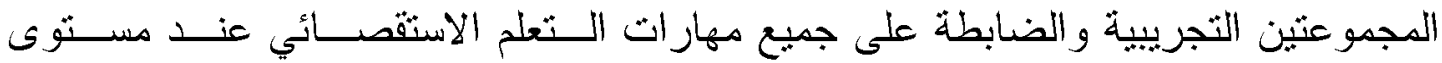

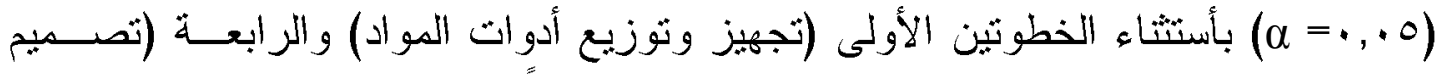

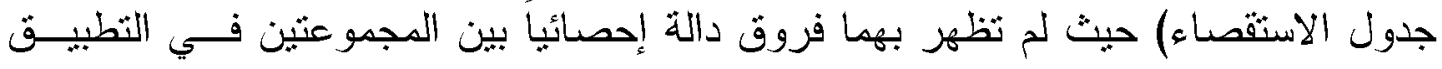

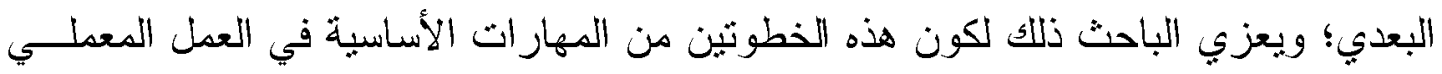

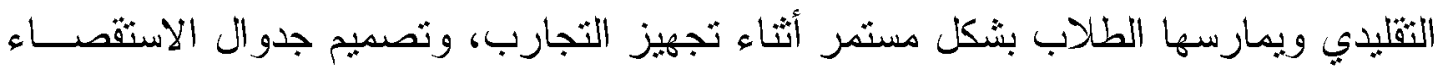

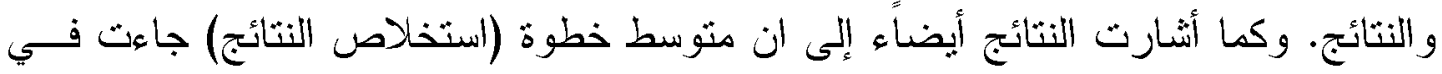

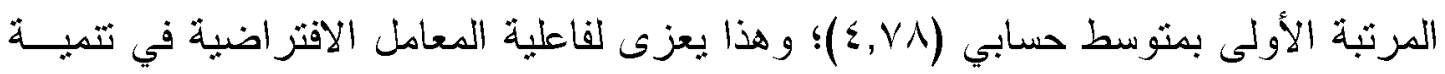

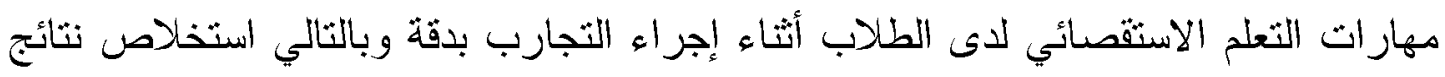

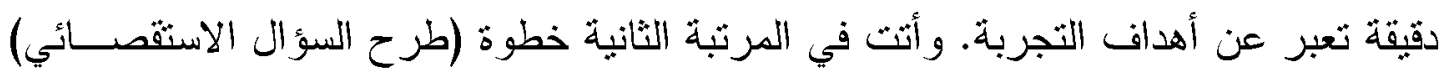

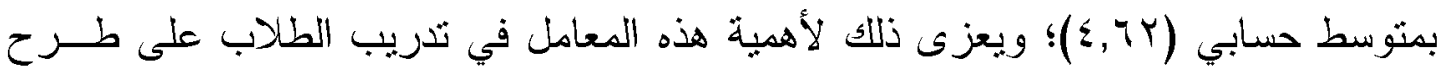

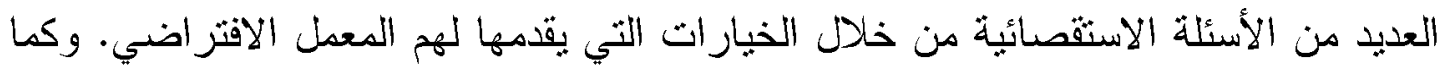

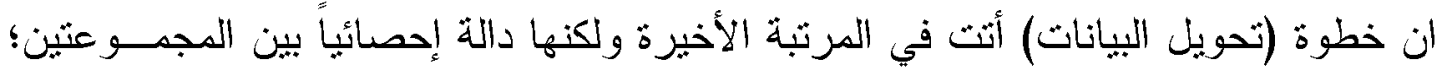

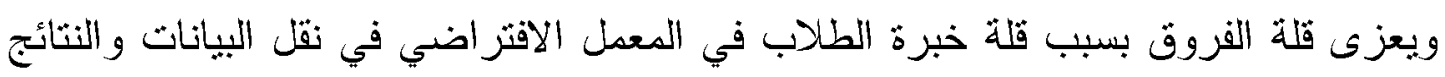

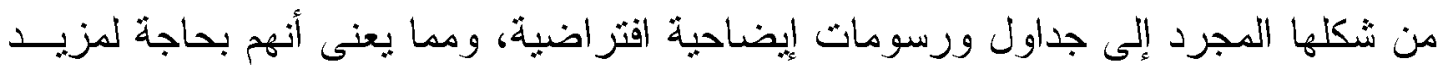

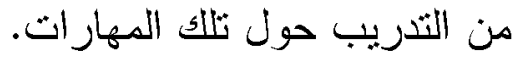




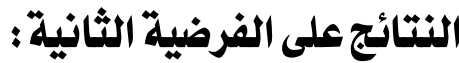

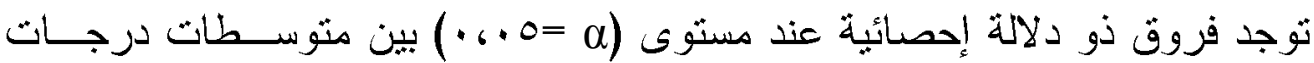
المجموعة التجريبية في التطبيقين القبلي والبعدي لبطاقة ملاحظة ونقيبم تتمبة مهارات التعلم الاستقصائي لصالح التطبيق البعدي.

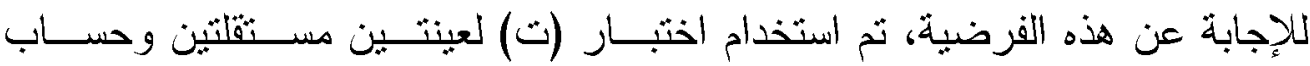
الهتوسطات الحسايية والإنحر افات المعيارية للهجموعة التجريبية في التطبيقين القبلي والبعدي لناي

$$
\text { كما يوضحها جدول رقم (ع): }
$$

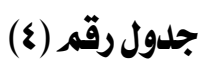

نتائج استخداه اختبار (ت) لعينتين مستقلتين وحساب المتوسطات الحسابية والانحر افات الميارية للمجموعة التجريبية في التطبيقين القبلي والبعليفي

\begin{tabular}{|c|c|c|c|c|c|c|}
\hline الدلالة & قيمة & الحرية & الالمياري & الحسابي & مهارات التعلم الاستقصائي & المجمومة \\
\hline \multirow{2}{*}{$* \bullet, \cdots$} & \multirow{2}{*}{$9, r r$} & \multirow[t]{2}{*}{ Vr } & $\cdot, Y \cdot r$ & $1, V \cdot$ & \multirow{2}{*}{ تجهيز وتوزيع أدوات المواد } & القبلي \\
\hline & & & 1, & $\varepsilon, \cdot r$ & & البعدي \\
\hline \multirow{2}{*}{$\cdot, 11$} & \multirow{2}{*}{$r, I r$} & \multirow{2}{*}{ Vr } & I,IV. & $r, Y Y$ & \multirow{2}{*}{ طرح السؤال الاستقصائي } & القبلي \\
\hline & & & $1,\{7\}$ & $\xi, \$ 7$ & & البعدي \\
\hline \multirow{2}{*}{$* \bullet, \cdots$} & \multirow{2}{*}{$r, \wedge \wedge$} & \multirow{2}{*}{ vr } & $\cdot, A \cdot Y$ & $r, v \cdot$ & \multirow{2}{*}{ تصميم التجربة } & القبلي \\
\hline & & & $1,0 . r$ & $\xi, \xi 9$ & & البعدي \\
\hline \multirow{2}{*}{$* \bullet, \cdots$} & \multirow{2}{*}{$\boldsymbol{\xi}, \wedge 1$} & \multirow{2}{*}{ rr } & $\cdot, 9 \leqslant Y$ & $r$ & \multirow{2}{*}{ تصميم جلدول الاستقصاء } & القبلي \\
\hline & & & $1,9 \mathrm{rq}$ & $\xi, \xi 9$ & & البعلي \\
\hline \multirow{2}{*}{$* \bullet, \cdots$} & \multirow{2}{*}{$7, \vee 9$} & \multirow{2}{*}{ rr } & $\cdot, 9 \cdot 1$ & $r, r$. & \multirow{2}{*}{ التنبؤ } & القبلي \\
\hline & & & 1,079 & $\varepsilon, 7\}$ & & البعدي \\
\hline \multirow{2}{*}{$* \bullet, \cdots$} & \multirow{2}{*}{$\xi, \xi q$} & \multirow{2}{*}{ rr } & $\cdot, 701$ & $r, \wedge \xi$ & \multirow{2}{*}{ تنفيذ التجربة وتسجيل الملاحظات } & القبلي \\
\hline & & & $1,0 . r$ & $\xi, \xi \wedge$ & & البعلي \\
\hline \multirow{2}{*}{$* \bullet, \cdots$} & \multirow{2}{*}{$7, \vee 7$} & \multirow{2}{*}{ rr } & $\cdot, 0 . r$ & r,or & \multirow{2}{*}{ تحويل البيانات } & القبلي \\
\hline & & & 1, rav & $\xi, Y Y$ & & 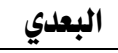 \\
\hline \multirow{2}{*}{$* \bullet, \cdots$} & \multirow{2}{*}{$\varepsilon, r V$} & \multirow{2}{*}{ rr } & $\cdot, 0 . r$ & r, TY & \multirow{2}{*}{ استخلاص النتائج } & القبلي \\
\hline & & & 1,711 & $\xi, 9 \Lambda$ & & 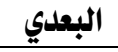 \\
\hline \multirow{2}{*}{$\cdot,+1$} & \multirow{2}{*}{$r, r q$} & vr & $1,9 \cdots$ & $r, r V$ & تقالـ التفسب ات & القبلي \\
\hline & & $r$ & $1,0 \leqslant 9$ & $\xi$, ro & 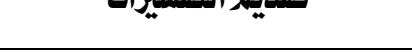 & 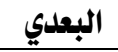 \\
\hline$* \ldots$ & 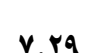 & $v_{r}$ & $\cdot, r \leqslant 7$ & $r, 1 \varepsilon$ & 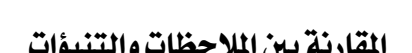 & القبلي \\
\hline , & ה & r & I,VYr & $\xi, Y \xi$ & 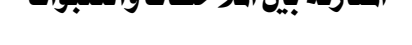 & البعدي \\
\hline$* \ldots$ & $9.9 \%$ & vr & A, ITO & YV,AT & 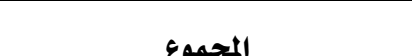 & القبلي \\
\hline , & 1, & & $10, r i r$ & $\{\xi, \Gamma \Psi$ & (n) & البعدي \\
\hline
\end{tabular}

$$
\alpha=\cdot \text { "دال عند مستوى دلالة } 0 \text {. }
$$


نلاحظ من الجدول السابق رقم (乏) أن منوسط أداء طلاب المجموعة التجريبية فــي النطبيق البعدي أعلى من متوسط أدائهم بالتطبيق القبلي على الأداة ككل، وكانت الفروف دالة التهاب

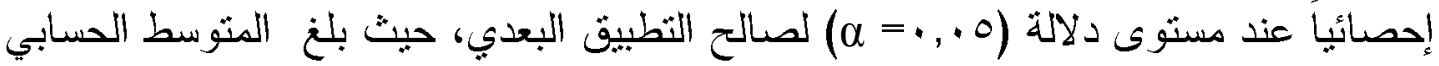

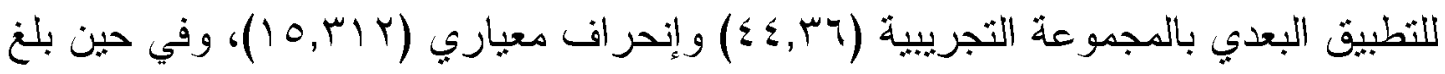

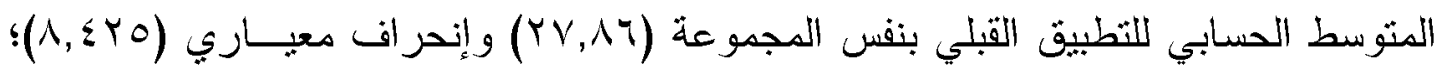
ويعزب الباحث ذلك إلى فعالية المعامل الافتراضية في تتمية مهارات الــنعلم الاستقصــائي

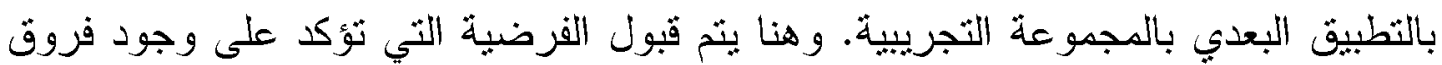

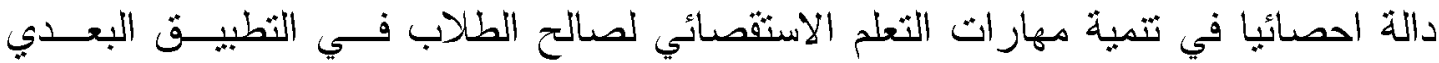

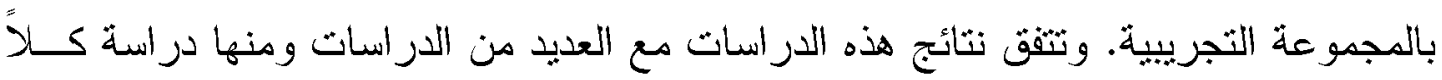

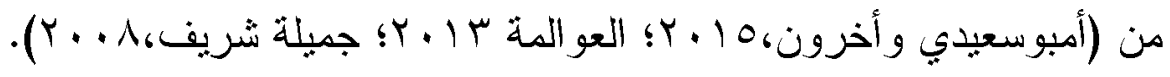

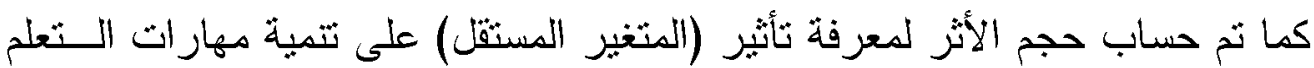

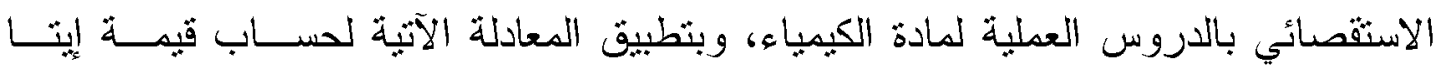

.(Kiess, 1996,p.513)

$$
n^{2}=\frac{t^{2}}{t^{2}+d f}
$$

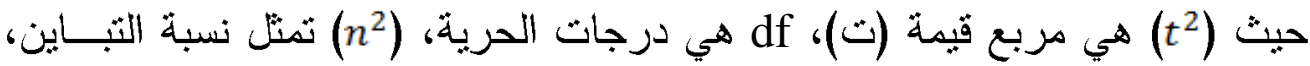

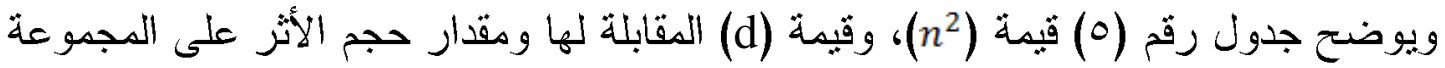

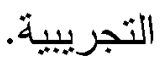

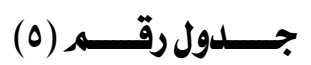

\begin{tabular}{|c|c|c|c|c|}
\hline التأثير & قيمة ( d ) & قيمة (n) & المتفير التابع & المتفير المستقل \\
\hline كبير & $\bullet, \wedge \xi$ & $\cdot, 17$ & تنمية مهارات التعلد الاستقصائي & المعلو الافتراضي \\
\hline
\end{tabular}

حجم الأثر باستخلاه معادلة ايتا

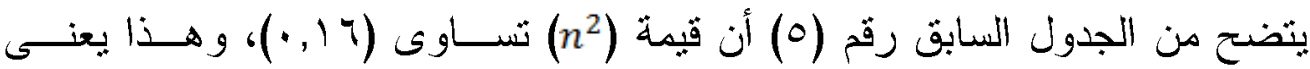

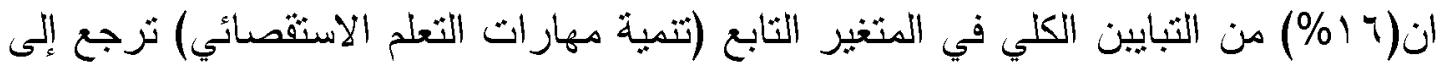
تاثير المتغير المسنقل وهو استخدام (المعطل الافتراضي)، وكما ان قيمة (d) تساوى (عی, •) 


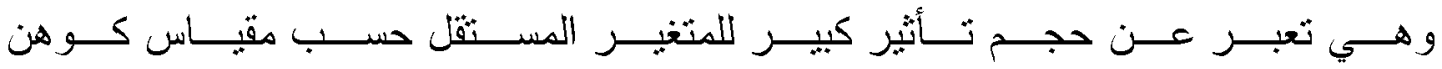

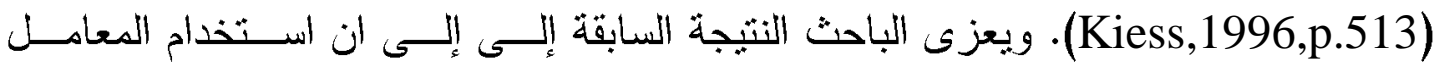
الافتر اضية بالمجموعة التجرييية أدت إلى مساعده الطلاب إلى ممارســة مهــار ات الــتعلم الاستقصائية بدقة أثناء تتفيذ خطوات التجارب الكيميائية بالدروس العملية بكراسة العملـي، العي،

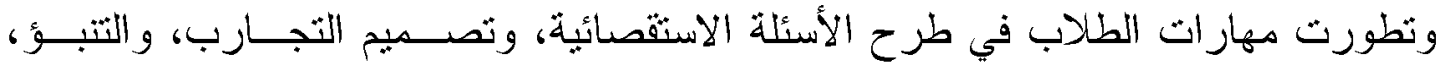

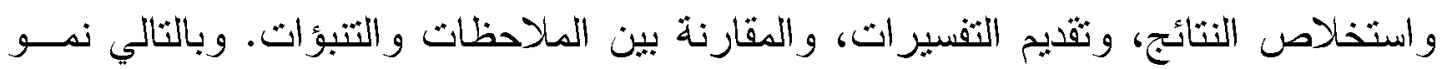
مهار ات التعلم الاستقصائية للديهم.

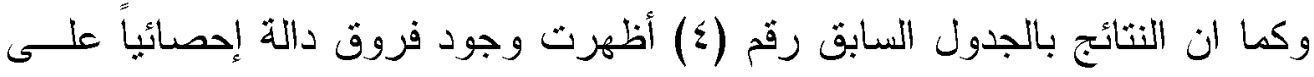

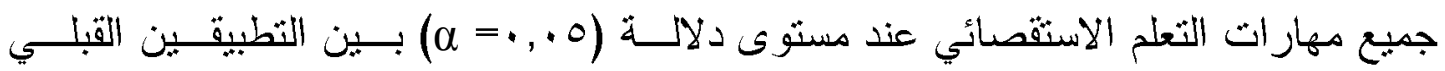

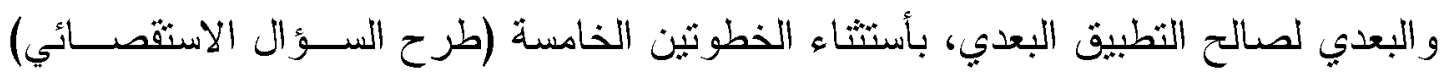

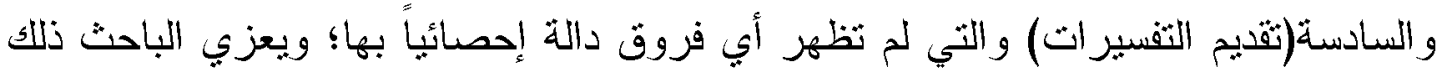
ان التجارب بالدروس العملية والتي تثبع خطوات التعلم التقليدية تدرب الطــلاب ونكســهـه

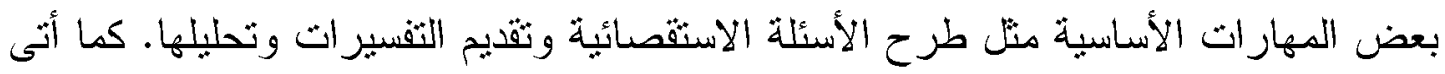

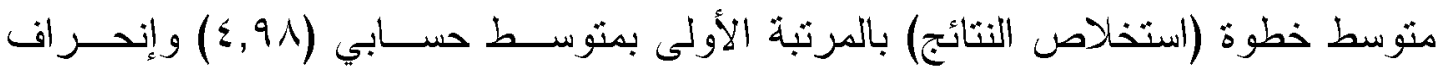

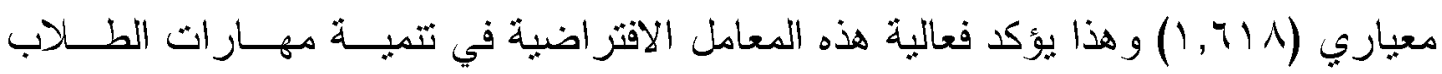
الاستقصائية، وفي استخلاص النتائج وتفسيرها، وكما أنى في المرتبة النانية خطوة (التتبــؤ)

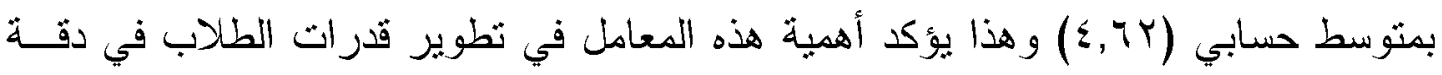

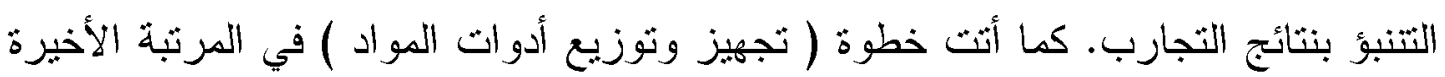

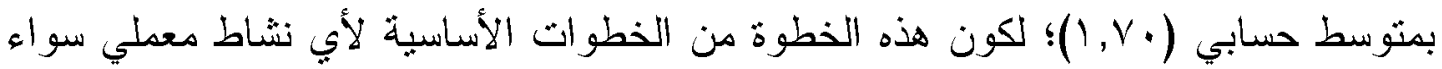

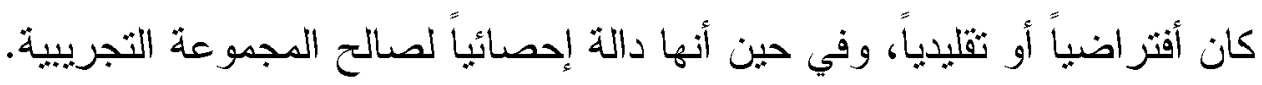

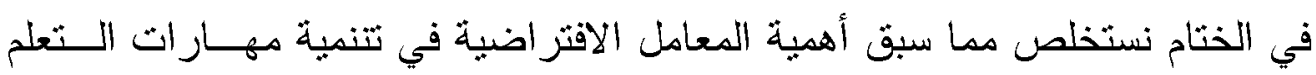

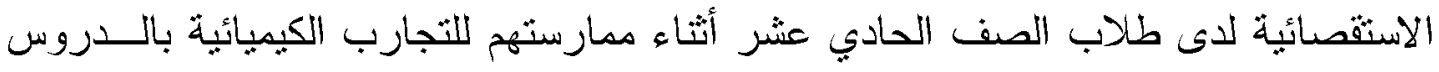

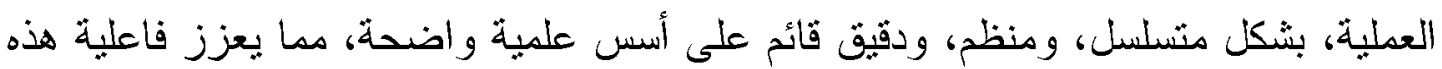

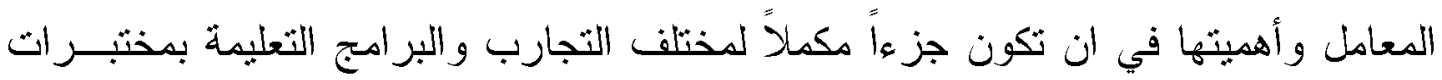

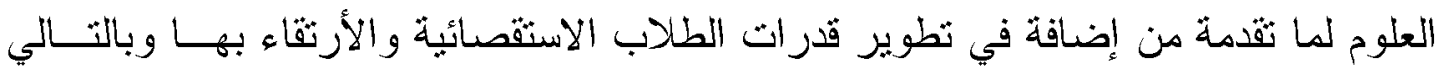
الأرتقاء بندريس العلوم ومخرجات النظام التعليمي. 


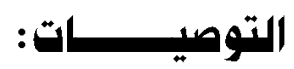

خلصت الاراسة للعديد من التوصيات:

ا- ضرورة اهتمام القائمين نطوير مناهج الكيمباء ومعامل العلــوم بالمعامـلـل الافتراضــية وأعنبار ها جز عاً مكملخً للمعامل الثقليدية.

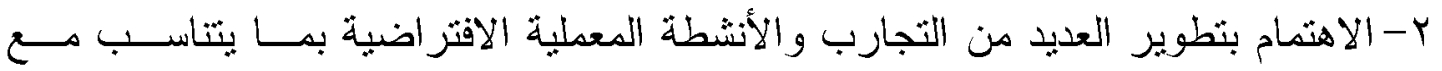
مناهجنا بشكل عام ومنهج الكيمباء بشكل خاص.

س-ثدريب المشرفين ودعلمي العلوم على كيفية استخدام المعامل الافتراضية فـي تـدريس التجارب وتوظيفها بشكل مناسب في تحقيق مهار ات التعلم الاسثثصائي.

ـ - ضرورة إدرك المعلمين والقائمين على النظام النعليمي بأهمية المعامل الافتر اضية فــي تتمية مهار ات التعلم الاستقصائي من خلال ممارستهم لمختلف التجارب. ه- القبام بدر اسات آخرى على استخدام المعامل الافقتر اضية على مناهج ومر احـل در اســية آخرى. (1) n

\section{دراسات وبنوث مقتر هة:}

1- أثز استخدام المعامل الافتز اضية على تتمبة مهار ات الأكتشاف العلمي لدى طلاب الحلقة الثانية من الثعليم الأساسي. ץ- اتجاهات معلمي العلوم نحو استخدام المعامل الافنز اضية في ثدريس العلوم والتحـديات التي ثواجه ذلك بالتعليم الأساسي. ب- أثر استخدام المعامل الافتراضبة في تدريس العلوم على تتمية الأحتفاظ بأثز التعلم لـدى لــ طلاب الحلقة الثانية من الثعليم الأساسي. 


\section{المراجـان}

" أمبوسعيدي، عبداله و البلوشي سليمان(9 ، . ب): طرائق تلديس العلوم سفاهيم وتطبيقات علمية، دار المسبرة للنشر و التوزيع، الأردن.

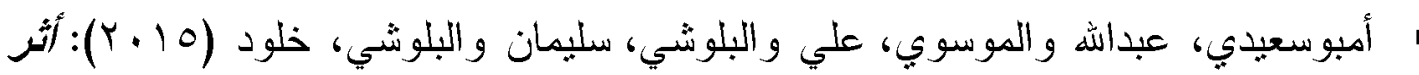
استذلام برنامج التصساح الكيميائي (Crocodile Chemistry) في تنميــة عدليـات

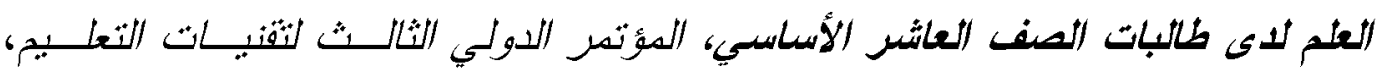
الجمعية العمانية لتقنيات التعليم، مارس 10 ـ ب، سلطنة عُمان.

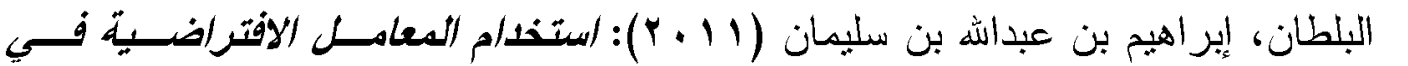
تلريس (العلوم بالمرطلة الثانوية في المدلكة العربية السعودية(الواقع وسبل التطــير)، رسالة ماجستير غير منشورة، جامعة أم القرى، المملكة العربية السعودية.

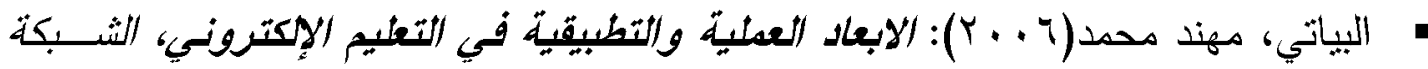

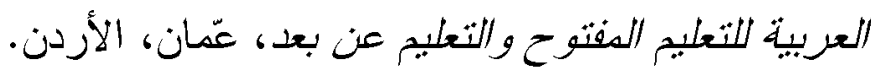

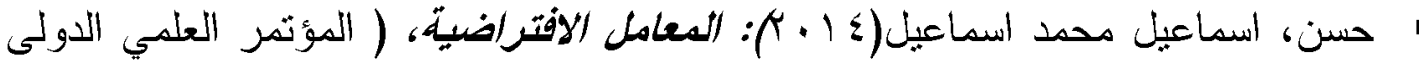

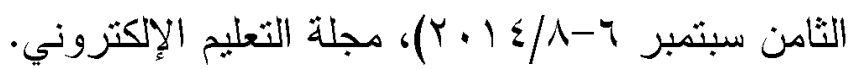

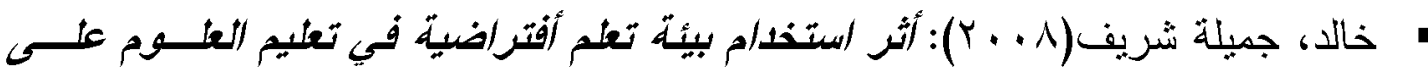

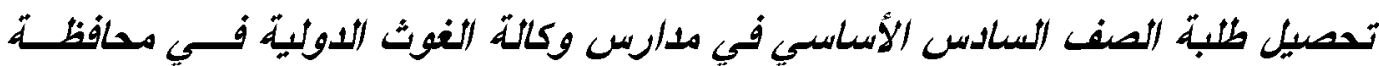
نابلس، رسالة ماجستير غير منشورة، فلسطين.

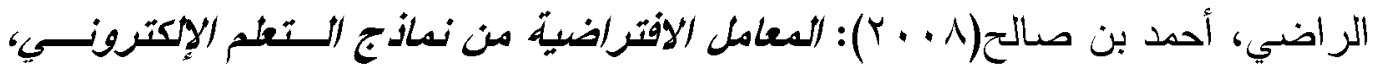

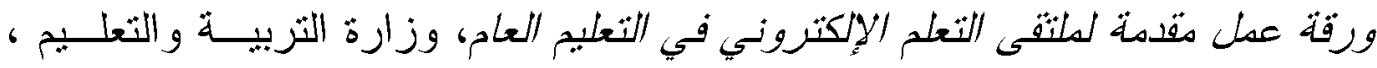

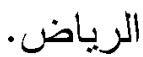

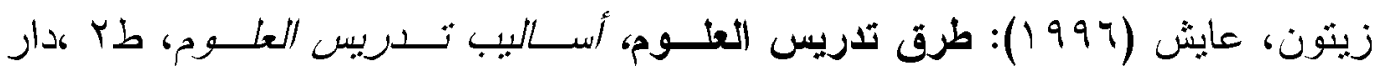

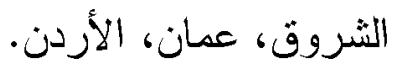

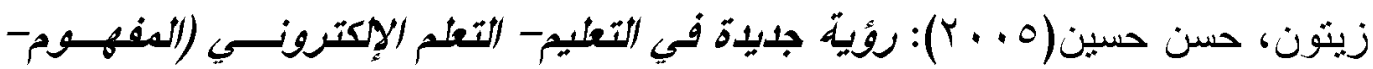

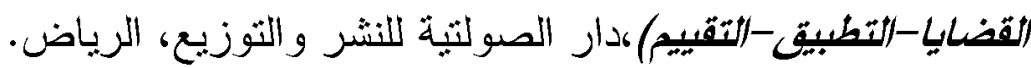

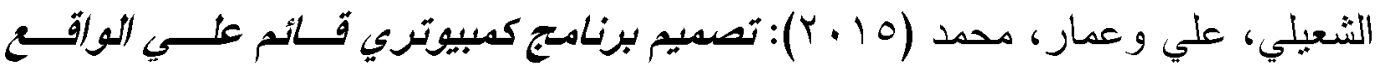

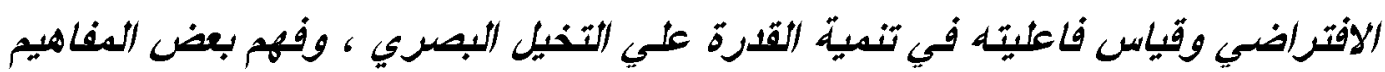

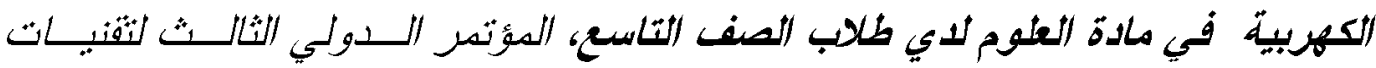
النعليم، الجمعية العمانية لتقنيات الثعليم، مارس 10 ــr، سلطنة عُمان. 


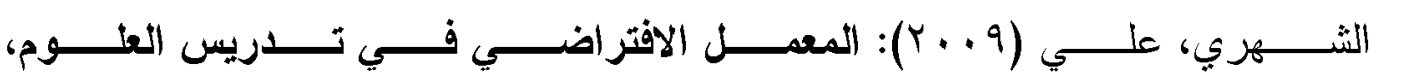
www.faifaonline.net/faifa/news-action-show-id-17317.htm

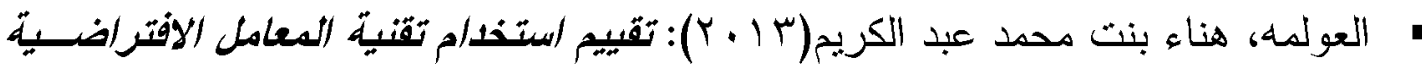

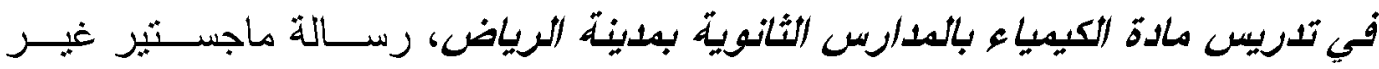

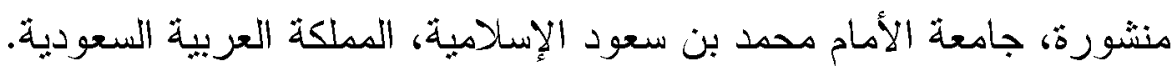

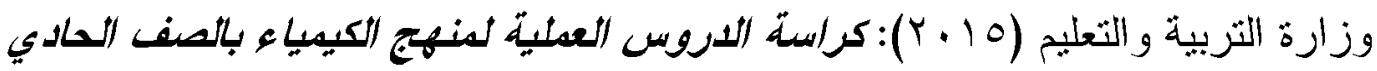
عشر بسلطنة عُدان.

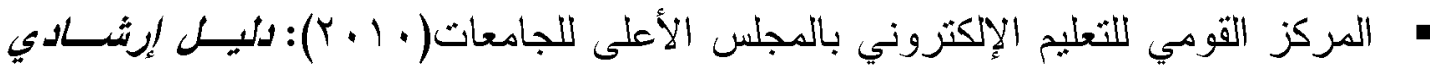

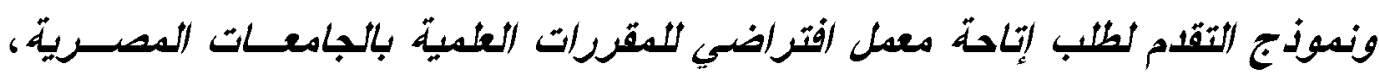

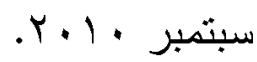

المناعي،عبداله سالم(1 . . ب): المختبرات الافتراضية، الجمعية العربية للتعليم و التدريب

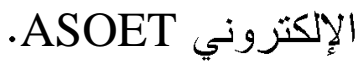

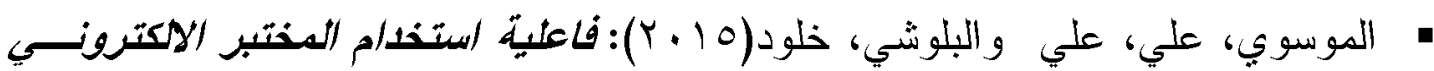

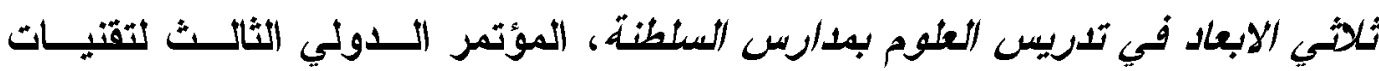

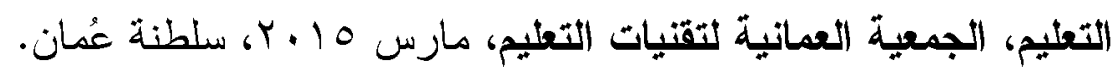

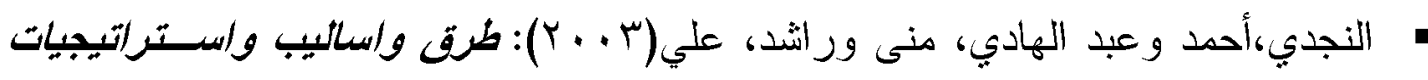
حليثة في تلريس العلوم، دار الفكر العربي، جمهورية مصر العربية.

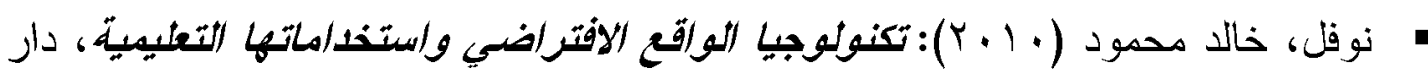
المناهج للنشر و الثوزيع، الأردن.

- Chris Dede et al (1996): Science space: Virtual Realities for Learning Complex and Abstract Scientific Concepts, Proceedings of IEEE Virtual Reality Annual International Symposium, pp246-253.

- Harry E. Keller \& Edward E. Keller (2005): Making Real Virtual Labs, The Science Education Review, $\operatorname{Vol}(4), \mathrm{No}(1)$.

- Herga, Nataša Rizman; Grmek, Milena Ivanuš and Dinevski, Dejan(2014): Virtual Laboratory as an Element of Visualization When Teaching Chemical Contents in Science Class, Turkish Online Journal of Educational Technology, TOJET, Vol(13), No(4),p p157-165.

- Kiess, H. O. (1996). Statistical concepts for the behavioral science, London, Sydney, Allyn and Bacon. 
- Tatli, Zeynep; Ayas, Alipasa(2012): Virtual Chemistry Laboratory: Effect of Constructivist Learning Environment, Turkish Online Journal of Distance Education, $\operatorname{Vol}(13), \operatorname{No}(1), \mathrm{p}$ p183-199.

- Tatli, Zeynep; Ayas, Alipasa(2011): Effect of a Virtual Chemistry Laboratory on Student's Achievement, Educational Technology \& Society, Vol(16), No(1),p p159-170.

- Slavko Kocijancic \& Colm O'Sullivan (2004): Real or Virtual Laboratories in Science Teaching is this Actually a Dilemma, Informatics in Education, $\operatorname{Vol}(3), \operatorname{No}(2), \mathrm{pp} 239-250$.

- WWW.Crocodile Chemistry.software.informer.com/60./ 


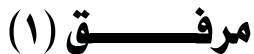

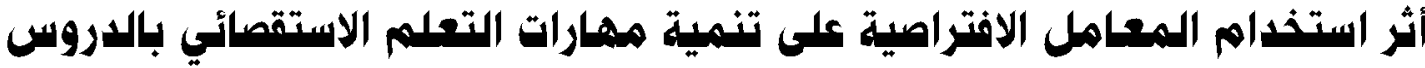

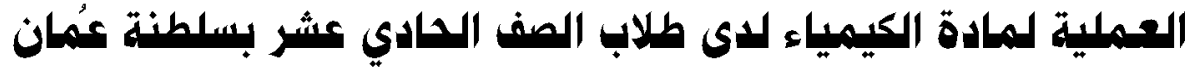

بيانات الطالب: رقم الطالب - ماتب

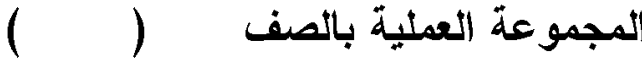

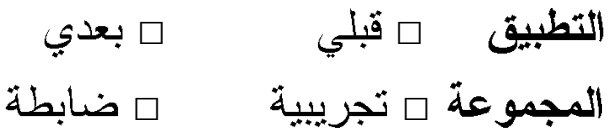

\begin{tabular}{|c|c|c|c|c|c|}
\hline \multicolumn{3}{|c|}{ الستويات } & \multirow{2}{*}{ المهــــــــــارات } & \multirow{2}{*}{ مهارات التعله الاستقصائي } & \multirow{2}{*}{ هـ } \\
\hline | ضعيف & متوسط & عالي & & & \\
\hline & & & تحديد المواد اللازمة للإستقصاء العملي & \multirow{2}{*}{ تجهيز ت ت ت توزيع أدوات المواد } & \multirow{2}{*}{1} \\
\hline & & & تجهيزوتصنيف الموادوترتبيها حسب خطوات التجربة & & \\
\hline & & & يطرح سؤال استقصائي على زملائة بالمجموعة & \multirow{2}{*}{ طرح السؤال الاستقصائي } & \multirow{2}{*}{ r } \\
\hline & & & يوضح الهلدف من السؤال الاستقصائي من خلال الموادو والأدوات & & \\
\hline & & & | وضع تصميم لخطوات التجربة للإجابة على السؤال الاستقصائي & \multirow{2}{*}{ تصمير التجربة } & \multirow{2}{*}{$r$} \\
\hline & & & يناقش الخطوات الاستقصائية للتجربة مع زملائة & & \\
\hline & & & يصمي جدول استقصائي لملاحظة متفيرات التجربة & \multirow{2}{*}{ تصميم جدول الاستقصاء } & \multirow{2}{*}{$\varepsilon$} \\
\hline & & & يصنف الجدول الاستقصائي عمليات العلد المراد قياسها & & \\
\hline & & & يكتب تنبؤاته لما قد يحدث بعد إجراء التجربة & \multirow{2}{*}{ التنبؤ } & \multirow{2}{*}{0} \\
\hline & & & يكتب تنبؤاته بالنتائج المتوقعة بعد الأنتهاء من التجربة & & \\
\hline & & & تنفيذ التجربة بشكل متسلسل حسب الخطوات الاستقصائية & \multirow{2}{*}{ تنفيذ التجربة وتسجيل } & \multirow{2}{*}{1} \\
\hline & & & جمع الملاحظات والبيانات عن التجربة وتدوينها & & \\
\hline & & & تحليل البيانات المستخلصة من التجربة & \multirow{2}{*}{ تحويل البيانات } & \multirow{2}{*}{$\mathrm{v}$} \\
\hline & & & تحويل البيانات إلى أشكال توضيحية ورسور بيانية & & \\
\hline & & & يستخلص الاستنتاجات & \multirow{2}{*}{ استخلاص النتائج } & \multirow{2}{*}{$\wedge$} \\
\hline & & & يستخلص التعميمات & & \\
\hline & & & يصصم جدول لتدوين التفسيرات & \multirow{2}{*}{ تقديم التفسيرات } & \multirow{2}{*}{9} \\
\hline & & & يقدم تفسيرات منطقية للنتائج & & \\
\hline & & & يقارن بين التنبؤات التي وضعها والنتائج التي حصل عليها & \multirow{2}{*}{ المقارنة بين الملاحظات } & \multirow{2}{*}{ 1. } \\
\hline & & & يقارن بين النتائج توصل إليها والنتائج بالمعمل الاقتراضي & & \\
\hline
\end{tabular}




\section{Abstract}

This study aims to identify the effect of using virtual laboratories in developing inquiry learning skills in practical lessons of chemistry in grade 11 in Oman. The sample was consisted of 72 Grade 11 students, distributed among 37 students of experimental group and 35 of control group. The first group used a virtual lab which is known as Crocodile Chemistry in their experiments and whereas the control group used only the traditional lab.

In order to achieve aims of the study, an observation checklist was used to evaluate students developing in inquiry learning skills in their chemical experiments in the virtual lab. This checklist consists of (10) major steps in inquiry-based learning and (20) minor skills. This instrument's validity was checked by handing out it to a group of professional arbitrators. The internal consistency of the reliability was calculated by Cronbach's Alpha Factor and it gave a value of (0.81). The study followed the quasiexperimental methodology, that is based on controlling of variables and conducting of observation and evaluation checklist, in addition of a post comparison between the experimental and control groups and a pre and post comparison of only the experimental group.

The results of this study revealed that there are statically significant differences for the overall total of the instrument with mean of (43.06) with respect to the experimental group and (35.64) for the control group, except for the two skills those without any significant differences (preparation and distribution of the materials and the designing of the inductive timetable).

The study also found that in impact of virtual laboratories on dependent variable was (0.87), this means of the impact of this labs on the students' performance of their practicing of the inquiry-based learning skills while using the normal chemical experiments. This was according to the excellence of these labs in their clearance, sequencing and accuracy. These labs give students more than one chance to practicing their experiments.

The results also showed that there are statically significant differences between the pre and post applications in respect of the post application for the experimental group with means of (44.36) for the post application and means of (27.86) for the pre application of the overall instrument expect these two steps those without any significant differences (asking the inquire question and give explanations).

The study recommends the importance of integrate the virtual labs in different studying levels, and train teachers how to use and implement these labs to develop students' practical skills. 